\title{
BRAIN EDEMA IN ACUTE LIVER FAILURE AND CHRONIC LIVER DISEASE: SIMILARITIES AND DIFFERENCES
}

\author{
Cristina R. Bosoi and Christopher F. Rose
}

Neuroscience Research Unit, Hôpital Saint-Luc (CRCHUM), Université de Montréal, Québec, Canada

Received 11 July 2012; Received in revised form 11 January 2013; Accepted 16 January 2013; Available online 31 January 2013

\section{ABSTRACT}

Hepatic encephalopathy (HE) is a complex neuropsychiatric syndrome that typically develops as a result of acute liver failure or chronic liver disease. Brain edema is a common feature associated with HE. In acute liver failure, brain edema contributes to an increase in intracranial pressure, which can fatally lead to brain stem herniation. In chronic liver disease, intracranial hypertension is rarely observed, even though brain edema may be present. This discrepancy in the development of intracranial hypertension in acute liver failure versus chronic liver disease suggests that brain edema plays a different role in relation to the onset of HE. Furthermore, the pathophysiological mechanisms involved in the development of brain edema in acute liver failure and chronic liver disease are dissimilar. This review explores the types of brain edema, the cells, and pathogenic factors involved in its development, while emphasizing the differences in acute liver failure versus chronic liver disease. The implications of brain edema developing as a neuropathological consequence of HE, or as a cause of HE, are also discussed.

\section{Highlights}

- Brain edema is a common feature in ALF and CLD.

- HE is inconsistently associated with the presence of brain edema.

- Fibrous and protoplasmic astrocytes are differentially implicated in the pathogenesis of HE.

- The pathogenesis of HE is multifactorial causing an array of neurological symptoms.

Abbreviations ALF, acute liver failure; CLD, chronic liver disease; HE, hepatic encephalopathy; MHE, minimal hepatic encephalopathy; ICP, intracranial pressure; MRI, magnetic resonance imaging; CBF, cerebral blood flow; BBB, bloodbrain barrier; BDL, bile duct-ligation; PCA, portacaval shunt; PAG, phosphate-activated glutaminase; GS, glutamine synthetase;ROS, reactive oxygen species

Keywords Acute liver failure; Chronic liver disease; Hepatic encephalopathy; Brain edema; Astrocyte swelling; Intracranial pressure

\section{INTRODUCTION}

Loss of liver function occurs as a consequence of either acute liver failure (ALF) or chronic liver disease (CLD). ALF is defined as a rapid hepatocellular necrosis that leads to the severe deterioration of liver function, which occurs within hours up to 6 months after the onset of jaundice, and in the absence of a pre-existing liver disease (Lee, 2012). The most frequent cause of ALF is drug intoxication and hepatotoxicity (58\%), with acetaminophen overdose being the most frequently observed (46\%). Other etiologies include autoimmune hepatitis, acute viral hepatitis (A and B), drug-induced, with a large proportion (15\%) remaining indeterminate. The mean survival rate (spontaneous liver regeneration) of patients with ALF is $45 \%$, but this can vary significantly depending on the etiology of ALF. The highest recovery rate (55-65\%) is reported in patients following acetaminophen overdose or hepatitis A infection (Lee, 2012).

Bosoi, C.R. \& Rose, C.F., 2013. Brain edema in acute liver failure and chronic liver disease: Similarities and differences. Neurochemistry International, 62(4), p.446-457. 
CLD develops due to a chronic deterioration of liver function resulting from a persisting, long-term hepatic insult. After 1020 years of continuous aggression, cirrhosis evolves, and is characterized by the progressive replacement of normal liver architecture by fibrosis, scar tissue and regenerative nodules (Fauci et al., 2011). The most common etiologies of cirrhosis are: (1) alcoholism, as 8-20\% of long-term heavy drinkers develop cirrhosis (Sanyal et al., 2010), (2) chronic viral hepatitis, where approximately $30 \%$ of infected patients become cirrhotic (Rosen, 2011), and (3) the accumulation of fat deposits in the liver, which cause non-alcoholic fatty liver disease (NAFLD) and non-alcoholic steatohepatitis (NASH). Given that obesity is on course of becoming a worldwide epidemic condition (in the USA, $66 \%$ of adults are overweight or obese; this is predicted to increase to 75\% by 2015 (Wang and Beydoun, 2007)), the number of cases of NASH-related cirrhosis is expected to rise.

To date, the only curative treatment for patients with liver failure or disease is liver transplantation. Since the number of patients awaiting a liver transplantation surpasses the number of available livers (from both living and cadaveric donors), managing liver failure/disease-related complications remains the primary challenge.

\section{HEPATIC ENCEPHALOPATHY}

Hepatic encephalopathy (HE), a major complication of both ALF and CLD, is a metabolic neuropsychiatric syndrome that comprises a spectrum of symptoms, ranging from mild cognition and attention deficits to coma and death. HE has been categorized into 3 types, based on the type of hepatic abnormality (Ferenci et al., 2002):

\subsection{Type A}

HE associated with ALF and characterized by a severe and rapid deterioration of mental status.

\subsection{Type B}

HE associated with portal-systemic shunting (by-pass), in which abnormal vascular connections are present between the portal vein and the systemic circulation, in the absence of intrinsic liver disease. As a result, gastrointestinal blood is diverted past the liver and enters directly into the systemic circulation, consequently exposing the brain to gut-derived toxins.

\subsection{Type C}

HE associated with cirrhosis (CLD), and portal-systemic shunting. As the duration and characteristics of neurological manifestations in CLD patients vary, this category has been subdivided into minimal and overt (episodic and persistent) HE. Minimal HE (MHE) is defined as subtle neuropsychological and neuropsychiatric changes without any clinically evident symptoms. It represents the mildest, subclinical form of HE, characterized by attention and cognition deficits detectable only by neuropsychological and neurophysiological testing. Present in 60-80\% of cirrhotic patients, MHE has a vital impact on their health-related quality of life, with an increased risk of having vehicle accidents ( Amodio, 2009 and Montgomery and Bajaj, 2011). Overt HE is clinically detectable, presenting with an unspecific symptomatology that has been classified into 4 grades according to the West Haven Criteria ( Conn et al., 1977). Symptoms range from sleep-wake rhythm alterations, shortened attention span, lack of awareness (grade I); lethargy, apathy, overt personality changes and disorientation (grade II); reaching somnolence, stupor, confusion (grade III); and coma (grade IV). Episodic HE is defined when cirrhotic patients demonstrate bouts of overt signs of HE. Persistent HE is defined when clinically obvious symptoms of HE are continuously present. Symptoms vary in onset, intensity and duration throughout each of these clinical forms and grades. Therefore, this suggests that the nature, severity and type of HE, in relation to degree and acuteness of liver disease/failure, may be associated with different pathophysiological mechanisms.

\section{BRAIN EDEMA IN LIVER DISEASE/FAILURE}

Brain edema is defined as an accumulation of water in the brain, which occurs in the setting of an osmotic gradient. It is commonly associated with HE in both ALF and CLD. Since the brain is contained within a non-compliant skull, an increase

Bosoi, C.R. \& Rose, C.F., 2013. Brain edema in acute liver failure and chronic liver disease: Similarities and differences. Neurochemistry International, 62(4), p.446-457. 
in brain volume can progressively result in an increase of intracranial pressure (ICP) and detrimentally lead to brain stem herniation and death.

\subsection{Evidence of brain edema in ALF and CLD}

Intracranial hypertension is the most feared complication, and it arises in $80 \%$ of ALF patients and leads to $25 \%$ mortality (Lee, 1993 and Mpabanzi and Jalan, 2012). Clearly, an increase in ICP entails the presence of brain edema. This has been proven in ALF patients using standard magnetic resonance imaging (MRI) $\mathrm{T}_{1}$ - and $\mathrm{T}_{2}$-weighted sequences (Fridman et al., 2009). On the contrary, patients with CLD very rarely develop intracranial hypertension. However, with more advanced, highly sensitive MRI $\mathrm{T}_{2}$-weighted sequences (ex. diffusion-weighted imaging (DWI) and magnetization transfer ration (MTR)), there is increasing evidence that brain edema is present in CLD patients (Córdoba et al., 2001, Häussinger, 2006, Kale et al., 2006, McPhail et al., 2012, Rovira et al., 2002, Shah et al., 2008 and Sugimoto et al., 2008). MRI provides a good contrast between soft tissues, based on their water content. It can assess water diffusion and differentiate between free water and macromolecule-bound water (McPhail et al., 2012). However, the high-operating cost of these sensitive imaging techniques limits their utilisation in clinical practice as a diagnostic device and therefore remains a research tool.

In animal models, two invasive techniques are commonly used to assess the presence of brain edema. The wet-dry technique, which is based on the weight measurement of brain tissue before and after complete dehydration, allows for the calculation and evaluation of the amount of water present in the brain. The specific gravimetric technique (Marmarou et al., 1978), is based on calculating the percentage of water from measuring the density of the tissue. Here, small pieces $\left(2 \mathrm{~mm}^{3}\right)$ of freshly dissected brain tissue are dropped into linear density gradient columns (prepared with two mixed solutions of kerosene and bromobenzene) and the density of the tissue is measured and the percentage of water is determined. Even though both these methods have been used to demonstrate the presence of brain edema in different animal models of ALF and CLD (Bosoi et al., 2011, Davies et al., 2009, Jiang et al., 2009a and Sen et al., 2006), the gravimetric technique has several advantages over the wet-dry technique, including a higher sensitivity and the use of smaller pieces of tissue, allowing for the percentage of water content to be evaluated in numerous brain regions (including higher spatial resolution).

Therefore, it is evident brain edema is present in both ALF and CLD patients and respective animal models.

\subsection{Relationship between intracranial pressure and brain edema}

The relationship between intracranial volume and ICP is not a linear one. The exponential relationship between brain volume and ICP allows for a certain increase in brain volume (within the cranium) to arise before ICP begins to climb (Fig. 1B). An increase in brain volume can occur as a result of an increase in one of the brain components: the cerebral tissue (representing $80 \%$ of the intracranial volume), the blood or the cerebrospinal fluid compartments (each accounting for $10 \%$ of brain volume - Fig. 1A, (Rengachary and Ellenbogen, 2005)).

Bosoi, C.R. \& Rose, C.F., 2013. Brain edema in acute liver failure and chronic liver disease: Similarities and differences. Neurochemistry International, 62(4), p.446-457. 

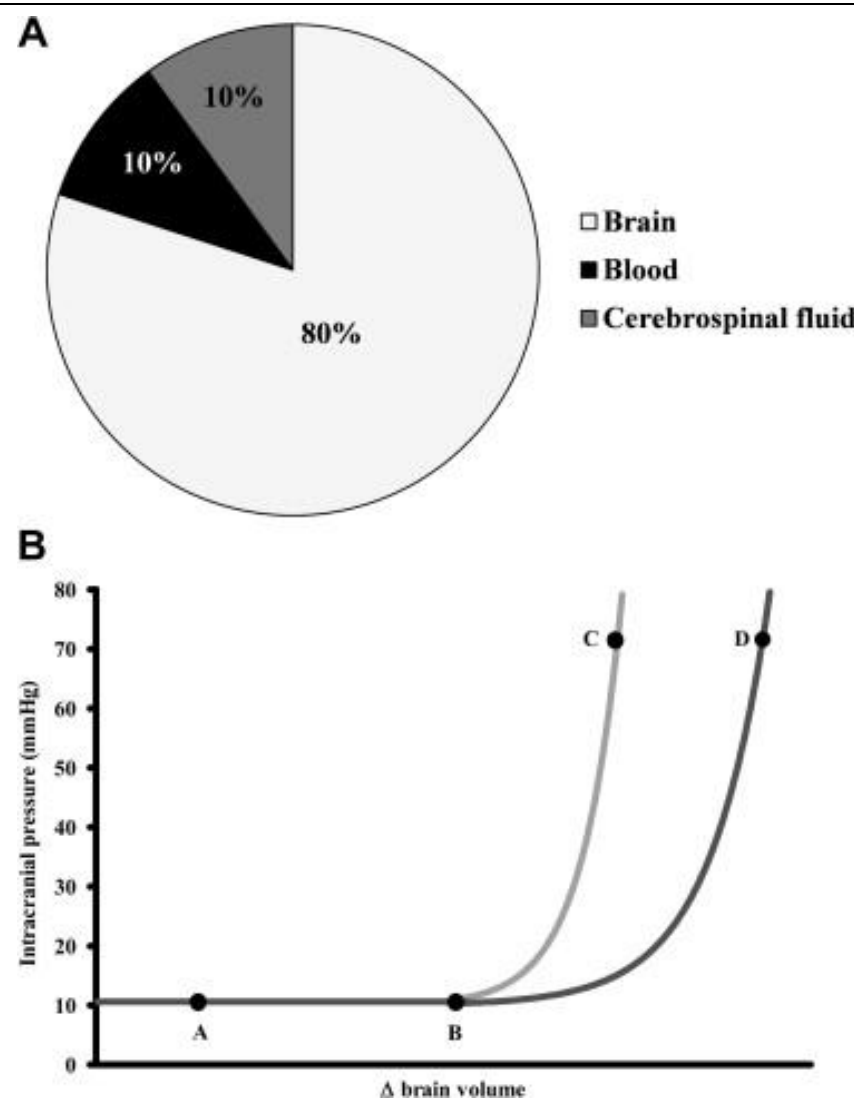

Fig. 1. (A) Cerebral constituents and their contribution to intracranial volume. (B) Relationship between brain volume and intracranial pressure: points A (healthy individuals) $\rightarrow$ B: a certain increase in brain volume does not lead to an increase in ICP; points B $\rightarrow$ C: exceeding the brain volume capacity leads to an increase in ICP as observed in ALF; points B $\rightarrow$ D: due to brain atrophy or alterations in brain volume constituents, a further increase in brain volume is required in order to initiate an increase in ICP.

Several theories have been proposed to explain the discrepancy between ALF and CLD in the development of intracranial hypertension. Firstly, it is possible that the degree of water accumulation in the brain found in ALF and CLD is not equivalent. In this case, higher quantities of water accumulate in the brain of ALF patients vs. CLD patients, which hence lead to an increase in ICP (Fig. 1B, points B $\rightarrow$ C). Similarly, this would entail that the increase in brain water found in CLD is less than the quantity found in ALF and, therefore, has been defined as "low-grade" brain edema (Fig. 1B, points $\mathrm{A} \rightarrow \mathrm{B}$ ) (Häussinger et al., 2000). A second explanation could be that the quantity of accumulated water in the brain parenchyma is similar in both ALF and CLD, but the volume of other brain constituents is altered (Fig. 1A).

An increase in cerebral blood flow (CBF) can contribute to brain edema through several mechanisms: an augmentation of water movement across the blood-brain-barrier (BBB), an increase in brain blood volume, or an uptake of toxins by the brain (Vaquero et al., 2004). CBF could be a differentiating factor involved in the development of intracranial hypertension in ALF vs. CLD. A decrease in CBF has been documented in patients with CLD (Almdal et al., 1989, Burra et al., 2004, Dam et al., 1998, Iversen et al., 2009, Iwasa et al., 2000 and Trzepacz et al., 1994), whereas an increase in CBF commonly occurs during ALF (Jalan et al., 2004a, Larsen et al., 1996, Strauss et al., 1997 and Wendon et al., 1994). Given that blood accounts for $10 \%$ of brain volume, a rise in CBF could contribute to intracranial hypertension, as observed in ALF. Similarly, a decrease in CBF, as observed in CLD, could prevent an increase in ICP. (Fig. 1B, points A $\rightarrow$ B).

Moreover, atrophy of the brain, characterized by a steady volume loss, has been demonstrated to occur with an increase in age (Hedman et al., 2011). This phenomenon also holds true for cirrhotic patients (Garcia-Martinez et al., 2011). Since the development of end-stage liver disease (cirrhosis) requires years of hepatic insults, approximately $80 \%$ of cirrhosis cases are diagnosed at 45 or later, with a median age of 56 years (Fleming et al., 2012). On the other hand, ALF patients tend to be

Bosoi, C.R. \& Rose, C.F., 2013. Brain edema in acute liver failure and chronic liver disease: Similarities and differences. Neurochemistry International, 62(4), p.446-457. 
younger (with a mean age $\approx 38$ years, as stated in a large cohort study by (Ostapowicz et al., 2002)); therefore, brain atrophy is less present in the latter. A smaller brain volume in CLD patients, due to age-related brain atrophy, grants more "space" for expansion in the eventuality of swelling and, therefore, requires a higher increase in brain volume constituents (compared to ALF), in order for intracranial hypertension to develop in CLD (Fig. 1B; points B $\rightarrow$ D). The precise contribution of physiological atrophy of the brain in preventing an increase in ICP remains based on indirect evidences and as such, further studies are required.

To summarize, an increase in ICP primarily arises in ALF patients and rarely develops in CLD, even though brain edema is present in both populations. This could be due to volume differences in brain components (tissue, blood) or to age-related atrophy and brain volume decreases.

\section{COMPONENTS INVOLVED IN THE DEVELOPMENT OF BRAIN EDEMA IN LIVER DISEASE/FAILURE}

Brain edema can arise due to cytotoxic or vasogenic mechanisms, with the first occurring as a result of alterations in cellular metabolism, and the latter due to a physical breakdown of the BBB (Klatzo, 1967). The BBB is a physical and metabolic barrier that helps regulate brain homeostasis and protects the brain from endogenous and exogenous toxins arising from systemic circulation. The BBB is a multicellular vascular structure, composed of endothelial cells with tight intercellular junctions surrounded by a basal lamina, astrocytes, and pericytes, which enables selected molecules (amino acids, metabolites, ions, etc.) to cross through specific channels and transporters. Like other biological membranes, water and gases diffuse passively across the BBB. Upon a physical breakdown of the BBB, plasma macromolecules (proteins) and other compounds that are normally disallowed to cross the BBB, enter into the extracellular space. In turn, an increase in osmotic pressure within the brain leads to a re-establishment of the osmotic equilibrium and, consequently, an increase in brain water uptake and vasogenic brain edema develops (Fig. 2, left side).

Proteins

- Ions

1. Amino acids

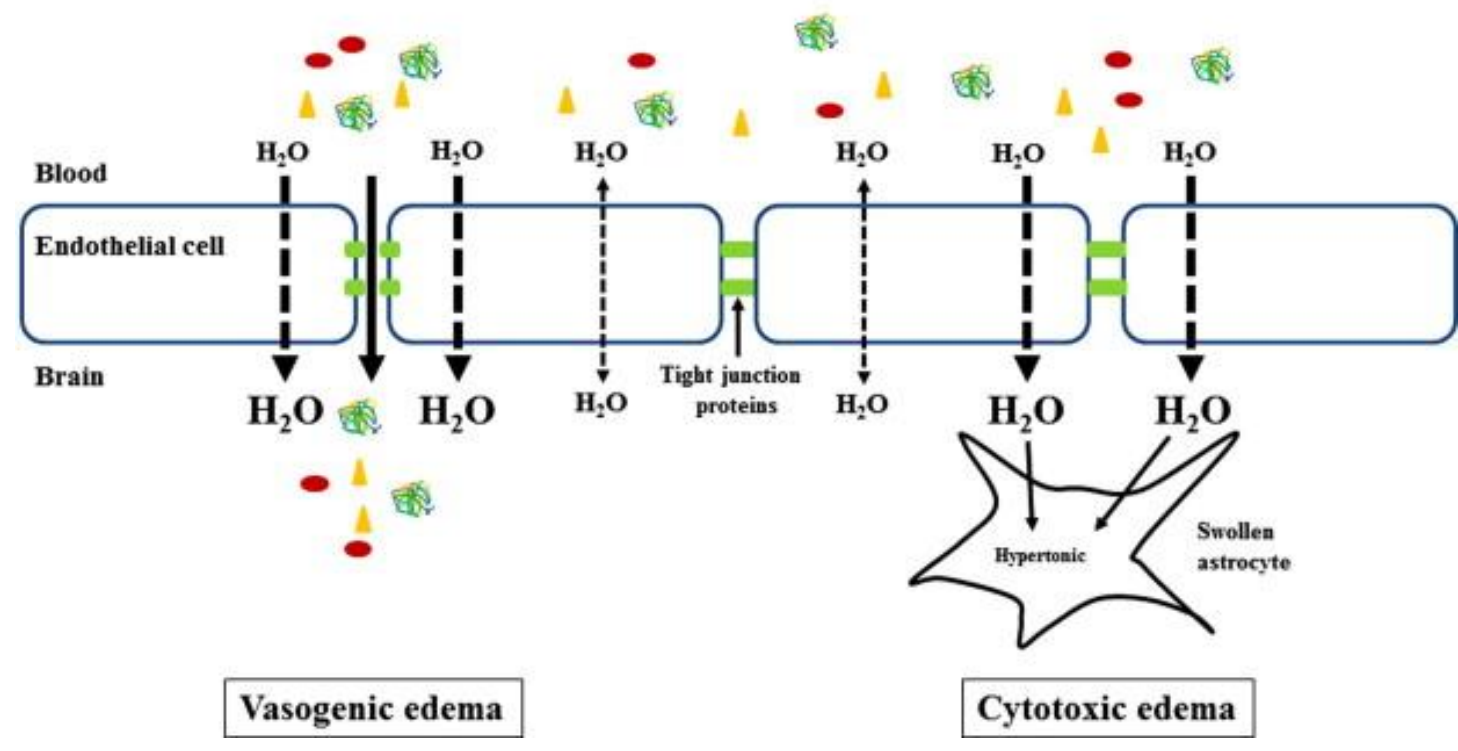

Fig. 2. Vasogenic and cytotoxic brain edema: left panel: vasogenic brain edema appears as a consequence of a physical breakdown of the BBB that allows plasma macromolecules (proteins) and other compounds to cross the BBB and accumulate in the extracellular space followed by an entry of water in attempt to re-establish the osmotic equilibrium and consequently results in brain edema; right panel: cytotoxic brain edema is the result of cellular metabolic alterations that 
cause an intracellular accumulation of osmotic molecules such as ions and amino acids, followed by an entry of water in order to re-establish the osmotic equilibrium.

Cytotoxic edema is the result of cellular metabolic alterations that cause an intracellular accumulation of osmotic molecules (becoming hypertonic), such as ions and amino acids, followed by an entry of water to re-establish the osmotic equilibrium (Klatzo, 1967) (Fig. 2, right side). Although, by definition, cytotoxic edema refers to intracellular swelling, it can also occur secondarily following an increase in permeability (not physical breakdown) of the BBB. Here, ions and amino acids, which normally pass through specific transporters located on the endothelial cells of the BBB, diffuse paracellularly or transcellularly into the brain. As the extracellular space represents an active part in cerebral metabolism and contributes to metabolite trafficking between cerebral cells, an increase in extracellular hypertonicity, in pathological conditions, can subsequently lead to an increase in cell transport and swelling (Lang et al., 1998).

Moreover, two recent studies demonstrated that altered cerebral endothelial function also contributes to brain edema. It was demonstrated that pathogenic factors associated with HE increase paracellular permeability in cultured endothelial cells (Skowrońska et al., 2012); moreover conditioned media from endothelial cells exposed to pathogenic factors associated with HE result in swelling of cultured astrocytes (Jayakumar et al., 2012). These in vitro studies demonstrate an active role of endothelial cells in the pathogenesis of brain edema, including their influence on astrocyte swelling.

\subsection{Vasogenic versus cytotoxic brain edema in ALF and CLD}

Animal models of ALF, specifically galactosamine and azoxymethane-induced, have demonstrated brain extravasation to Evans Blue and $\left[{ }^{14} \mathrm{C}\right]$ alpha-aminoisobutyric acid (Cauli et al., 2011, Dixit and Chang, 1990, Horowitz et al., 1983 and Yamamoto and Nguyen, 2006). In the same models, alterations in the expression of the major BBB tight junction proteins (occludin, claudin-5, zonula occludens 1 and 2) have been observed (Chen et al., 2009, Lv et al., 2010, Sawara et al., 2009 and Shimojima et al., 2008). However, in galactosamine-induced ALF in the rabbit, it was reported that capillary endothelial cells appeared normal, and no evidence of brain extravasation to horseradish peroxidase was observed (Traber et al., 1987), contradicting the anterior data. In another model of ALF, induced by hepatic devascularisation, inconsistent results have also been recorded: in pigs, perivascular and interstitial edema, along with a disruption of the pericytic and astrocytic processes in the frontal cortex, cerebellum and brain stem have been described (Kristiansen et al., 2010), while in rats, capillary endothelial vesicles were increased, but the BBB remained intact (Potvin et al., 1984). Overall, these inconsistencies may be due to differences in the use of animal species, models of ALF (etiology of ALF; toxins/surgical procedures), as well as the time of evaluation of the BBB (temporal resolution), given that evaluations were taken at different stages of HE severity.

Advanced MRI techniques, such as DWI, allow for a non-invasive method to differentiate between vasogenic and cytotoxic brain edema. By calculating the apparent diffusion coefficient (ADC), the diffusivity of water molecules can be quantified. Given that low ADC values were found in both ALF patients and animal models of ALF, these MRI studies support a cytotoxic origin of brain edema, thus corresponding to an increase in intracellular water (Chavarria et al., 2010, Rai et al., 2008, Ranjan et al., 2005 and Saksena et al., 2008).

Up to now, in CLD, the BBB has been primarily evaluated in cirrhotic rats induced by bile duct-ligation (BDL) in the presence of brain edema. Wright et al., using electron microscopy, precisely demonstrated that the BBB is anatomically intact in BDL rats (Wright et al., 2007). Furthermore, in the same model, our group did not find any brain extravasation of Evans Blue or sodium fluorescein (Bosoi et al., 2012), nor any changes in the expression of the tight junction proteins (Huynh et al., 2011). In another rat model of chronic HE, induced by a portacaval anastomosis (PCA), breakdown of the BBB could also not be demonstrated (Alexander et al., 2000). It is important to note that all the above-mentioned studies involved rat models of MHE and, therefore, it remains to be determined whether BBB breakdown is associated with overt HE. Interestingly, a recent MRI study by Chavarria and colleagues, proved that both cytotoxic and vasogenic mechanisms exist in cirrhotic patients (Chavarria et al., 2011).

In summary, brain edema in ALF principally remains of cytotoxic origin, with some evidence of BBB breakdown having been reported. In CLD, with the vast majority of the evidence suggesting that the BBB is structurally intact, it is conclusive that the pathogenesis of brain edema is due to cytotoxic mechanisms. Nevertheless, a role for increased permeability (not

Bosoi, C.R. \& Rose, C.F., 2013. Brain edema in acute liver failure and chronic liver disease: Similarities and differences. Neurochemistry International, 62(4), p.446-457. 
physical breakdown) of the BBB cannot be excluded and the co-existence of both cytotoxic and vasogenic mechanisms warrants further investigation.

\subsection{Astrocyte swelling and brain edema in liver disease/failure}

A cardinal feature of HE is astrocyte swelling. This has been proven by electronic microscopy in rabbits with galactosamine-induced ALF (Traber et al., 1987). In addition, marked intracellular swelling of the perivascular astroglial foot processes was present in patients who died in ALF-induced coma (Kato et al., 1992). In vitro experiments have also reported astrocyte swelling, by assessing the intracellular space using $\left[{ }^{3} \mathrm{H}\right]-3-O$-methylglucose ( Norenberg et al., 1991), or by microscopic measurements of cellular volume ( Hirrlinger et al., 2008), following the addition of pathogenic factors associated with HE. In CLD, astrocytes present a characteristic morphology, known as Alzheimer type II astrocytosis: large, swollen cells with enlarged swollen nuclei and cytoplasm, margination of chromatin, mitochondrial and rough endoplasmic reticulum proliferation and accumulation of glycogen ( Norenberg, 1977). Using electron microscopy, swollen astrocytes have also been demonstrated in cirrhotic rats ( Wright et al., 2007).

In contrast to astrocytes, neuronal swelling has rarely been documented. Only one study demonstrated morphological changes suggestive of neuronal swelling in ALF (hepatic devascularized) pigs in the frontal cortex, cerebellum and brain stem (Kristiansen et al., 2010). This electron microscopy study suggests for the first time that there are alterations in neuronal morphology (with indications of neuronal cell death) in the context of ALF. This depicts that neuronal degeneration may exist in the setting of liver failure (Butterworth, 2007), which could be a possible explanation for the persisting neurological complications that develop in patients following liver transplantation (Amodio et al., 2007, Frederick, 2012 and Guarino et al., 2006).

Metabolic differences between neurons and astrocytes explain the dissimilar propensity for swelling of these two cell types. Cross-talk between neurons and astrocytes is vital for individual cell function, and intense trafficking of several molecules arises between these cell types. Astrocytes provide metabolic support for neurons by supplying substrates as well as clearing and metabolizing molecules and products, which neurons cannot. Swelling of the astrocyte not only affects its proper function but also impairs the cross-talk to neurons altering overall cerebral function, thus enabling a pathological environment characterizing HE (Kimelberg, 2005).

Significant differences in regards to mechanisms of volume regulation exist between neurons and astrocytes (PasantesMorales and Cruz-Rangel, 2010). For example, following hypo-osmotic stress in normal mice, water entry was evidenced only in astrocytes and not in neurons (Nase et al., 2008), suggesting that neurons are more effective in preserving their volume in abnormal osmotic conditions. This difference can be explained by dissimilar metabolic and transport characteristics of the two types of cells, including osmotic gradients and ionic fluxes through membrane channels (Kelly and Rose, 2010 and Olson and $\mathrm{Li}, 2000$ ).

\subsection{White and gray matter: residence to different types of astrocytes}

Two major types of astrocytes have been identified based on their morphology: protoplasmic, mainly found in gray matter, and fibrous, mainly found in white matter (Bignami and Dahl, 1974) (Fig. 3). Protoplasmic astrocytes have rich branched processes, each surrounding a large number of synapses ( 20,000-120,000 in rodents and $\sim 270,000-2$ million in humans). In the white matter, fibrous astrocytes are significantly larger than protoplasmic astrocytes, with equally spaced cell bodies and unbranched straight processes orientated in the direction of axon bundles (Oberheim et al., 2009). Recently, other morphological types of astrocytes, such as interlaminate and varicous, have been described in gray matter, in both human and primate brains. These types of astrocytes are not present in rodents and their metabolic characteristics and functional role remain unknown (Oberheim et al., 2009). 

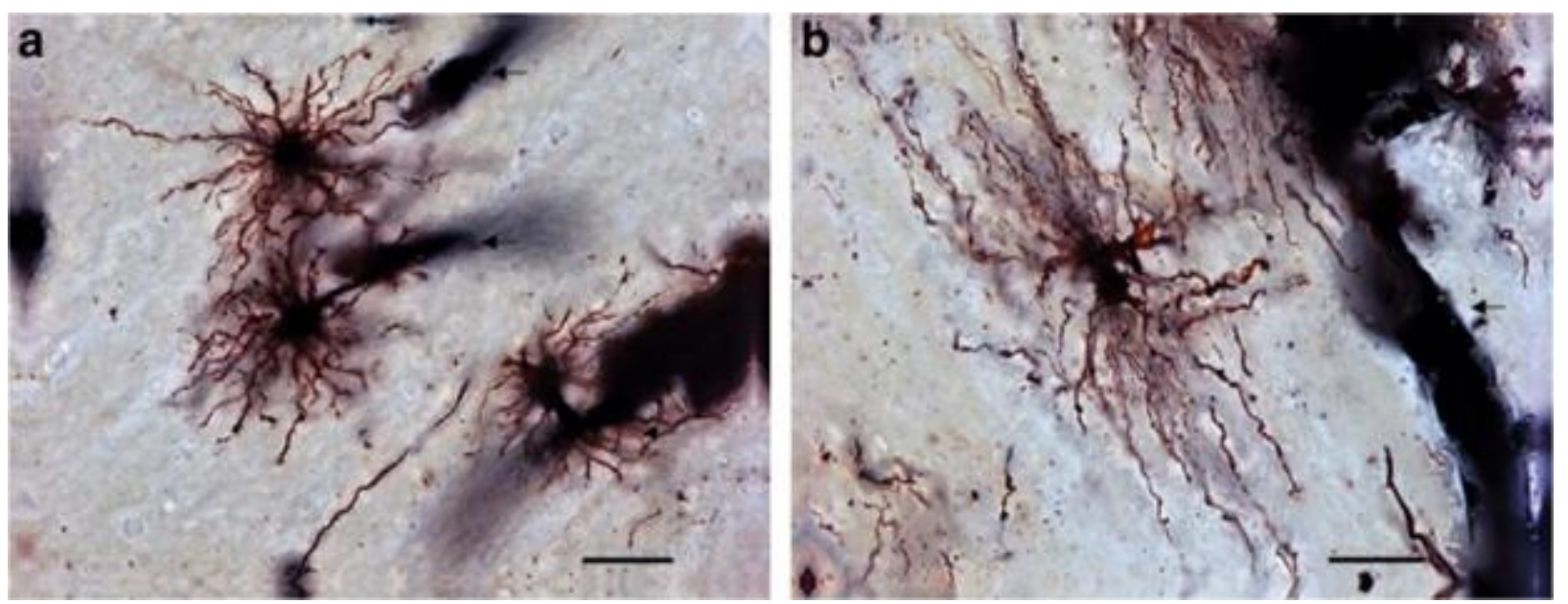

Fig. 3. Protoplamic and fibrous astrocytes in human brain. (a) Protoplasmic astrocytes, found in gray matter (cingulate cortex shown above), have rich branched processes, surrounding a large number of synapses; (b) fibrous astrocytes, characteristic to white matter, are larger than protoplasmic astrocytes, with unbranched straight processes. Golgi-staining, scale bar $10 \mu \mathrm{m}$ and $25 \mu \mathrm{m}$ respectively, arrows represent contacts between astrocyte processes and blood vessels. Reprinted after Torres-Platas et al., Neuropsychopharmacology. 2011 Dec; 36(13):2650-8 with the editor's permission.

The pathological implications of protoplasmic and fibrous astrocytes are poorly understood. Differential sensitivity between protoplasmic and fibrous astrocytes has been described in Parkinson's disease (Song et al., 2009) and cerebral ischemia (Lukaszevicz et al., 2002). A study performed on brain tissue from patients who died with Wilson's disease demonstrated that Alzheimer type II astrocytes originate from the fibrous type of astroglia (Bertrand et al., 2001). In the setting of HE, brain edema is found not only in both the gray matter, but also in white matter. Increased brain water has been demonstrated in the corticospinal tract of cirrhotic patients, which is related to motor tract dysfunction (Córdoba et al., 2003). Moreover, several studies have shown differences in the temporal development of brain edema in gray vs. white matter, and in their response to treatment. In pigs with ALF, water content in white but not in gray matter, was normalized following albumin dialysis by MARS (molecular adsorbent recirculating system), implying that white matter swelling may be more labile (Sen et al., 2006). A similar pattern was observed in CLD, as brainstem was more responsive to treatment with AST-120 (ammonia adsorbent oral carbon microspheres), compared to frontal cortex in BDL rats (Bosoi et al., 2011). A study in humans with different grades of HE demonstrated a significant increase of water content in white matter that correlated with the severity of HE. No such relationship was established for gray matter (Shah et al., 2008). These results suggest that fibrous astrocytes (white matter) are more susceptible to swelling than protoplasmic astrocytes (gray matter), and that white matter is more amenable to treatment.

Overall, protoplasmic and fibrous astrocytes are morphologically and biochemically distinct (Miller and Raff, 1984) and therefore their degree of susceptibility to pathogenic factors may be atypical.

\section{PATHOGENESIS OF BRAIN EDEMA IN ALF AND CLD}

\subsection{Ammonia}

The neurotoxic effects of ammonia have long been considered the main pathogenic factor in HE (Cooper and Plum, 1987). Ammonia is a neurotoxin whose homeostasis is maintained primarily by the liver. It is produced by a number of different metabolic reactions, with phosphate-activated glutaminase (PAG) being an important enzyme catalyzing the deamination of glutamine to glutamate. The gut is a primary source of ammonia production through ammonia-generating intestinal bacteria and PAG activity in the enterocytes. Gut-derived ammonia is then absorbed into the portal venous system, delivered to the liver and detoxified through the urea cycle. In the presence of liver disease/failure, a functionally impaired urea cycle leads to the development of hyperammonemia. Under these pathophysiological conditions, the enzyme glutamine synthetase (GS)

Bosoi, C.R. \& Rose, C.F., 2013. Brain edema in acute liver failure and chronic liver disease: Similarities and differences. Neurochemistry International, 62(4), p.446-457. 
becomes the primary ammonia detoxifying pathway, for it incorporates ammonia into glutamate forming glutamine. GS is present in the muscle, kidney, liver and brain, and has become a therapeutic target for ammonia-lowering strategies in $\mathrm{HE}$ (Rose, 2012).

Ammonia exists as a gas $\left(\mathrm{NH}_{3}\right)$ and as an ion (NH4+), with the equilibrium between the two being defined by the Henderson-Hasselbach equation. At a physiological $\mathrm{pH}$ (7.4), $98 \%$ of ammonia is present as $\mathrm{NH} 4+$ and only $2 \%$ as $\mathrm{NH}_{3}$. The gaseous $\mathrm{NH}_{3}$ can cross all plasma membranes through passive diffusion and $\mathrm{NH} 4+$, and, due to similar ionic properties to those of $\mathrm{K}^{+}$, can also cross biological membrane through $\mathrm{K}^{+}$channels, such as inward rectifying and voltage gated $\mathrm{K}^{+}$channels, as well as $\mathrm{K}^{+}$cotransporters $\left(\mathrm{Na}^{+} / \mathrm{K}^{+}\right.$and $\mathrm{H}^{+} / \mathrm{K}^{+}$ATPase, $\mathrm{Na}^{+}-\mathrm{K}^{+}-\mathrm{Cl}^{-}$cotransporters) (Aickin et al., 1982 and Moser, 1987). Therefore, these properties also imply that systemically derived ammonia, both as a $\mathrm{NH}_{3}$ and $\mathrm{NH} 4+$ can easily cross the BBB. Therefore under conditions of hyperammonemia, toxic levels of brain ammonia arise (Bosoi and Rose, 2009).

In ALF, arterial ammonia concentrations have been demonstrated to correlate with ICP, severity of clinical presentation, and death by brain herniation (Bernal et al., 2007, Clemmesen et al., 1999 and Tofteng et al., 2006). This suggests a direct link between hyperammonemia, brain ammonia and ICP (possibly brain edema). In CLD, HE patients often present elevated arterial ammonia concentrations; however, in contrast with ALF, the correlation between ammonia and severity of HE remains controversial (He et al., 2011, Kundra et al., 2005, Nicolao et al., 2003, Ong et al., 2003 and Weissenborn et al., 2007). This infers other factors may be implicated in the pathogenesis of HE.

\subsection{Glutamine/Glutamate}

Glutamine and glutamate are considered to be major organic osmolytes in the brain: glutamine represents $\sim 1.5 \%$ and glutamate 5\% of the total brain osmolytes (including ions and small organic molecules (Pasantes-Morales and Cruz-Rangel, 2010)). Both are involved in the regulation of brain volume (Gullans and Verbalis, 1993).

Glutamine is a pivotal player in the homeostasis of ammonia. In the brain, GS, which is found specifically in astrocytes, catalyzes the amination of ammonia to glutamate forming glutamine (Martinez-Hernandez et al., 1977). Whereas PAG, primarily found in the neurons, metabolizes glutamine to glutamate and ammonia (Hogstad et al., 1988). Together, these cell-specific reactions form the glutamate-glutamine metabolic cycle between astrocytes and neurons, whose role is to recycle the glutamate that has been released from neurons through astrocytes, thus preventing neuronal excitotoxicity (Cooper, 2001). Briefly, the glutamate released into the synaptic space by presynaptic neurons induces post-synaptic signaling through glutamate receptors, and is cleared by astrocytic excitatory amino acid transporters (EAAT1 and EAAT2, (Gegelashvili et al., 2007 and Rothstein et al., 1994)), and then converted into glutamine through GS. The non-neuroactive glutamine is released into the extracellular space through astrocyte glutamine transporters ( $\mathrm{N}$ and ASC-system transporter SN-1, SN-2 and ASCT2 (Chaudhry et al., 1999, Cubelos et al., 2005 and Dolińska et al., 2004)), and taken up by neurons (sodium-coupled amino acid transporter, SAT/ATA (Varoqui et al., 2000)), where it is converted back to glutamate via the action of PAG, in order to replenish the neurotransmitter pool. Therefore, astrocytic glutamate uptake prevents glutamate accumulation in the synaptic cleft and over-excitation of the postsynaptic neuronal receptors (Fig. 4A). Dysregulation of the glutamate-glutamine cycle could thus lead to impaired cerebral function.

Bosoi, C.R. \& Rose, C.F., 2013. Brain edema in acute liver failure and chronic liver disease: Similarities and differences. Neurochemistry International, 62(4), p.446-457. 

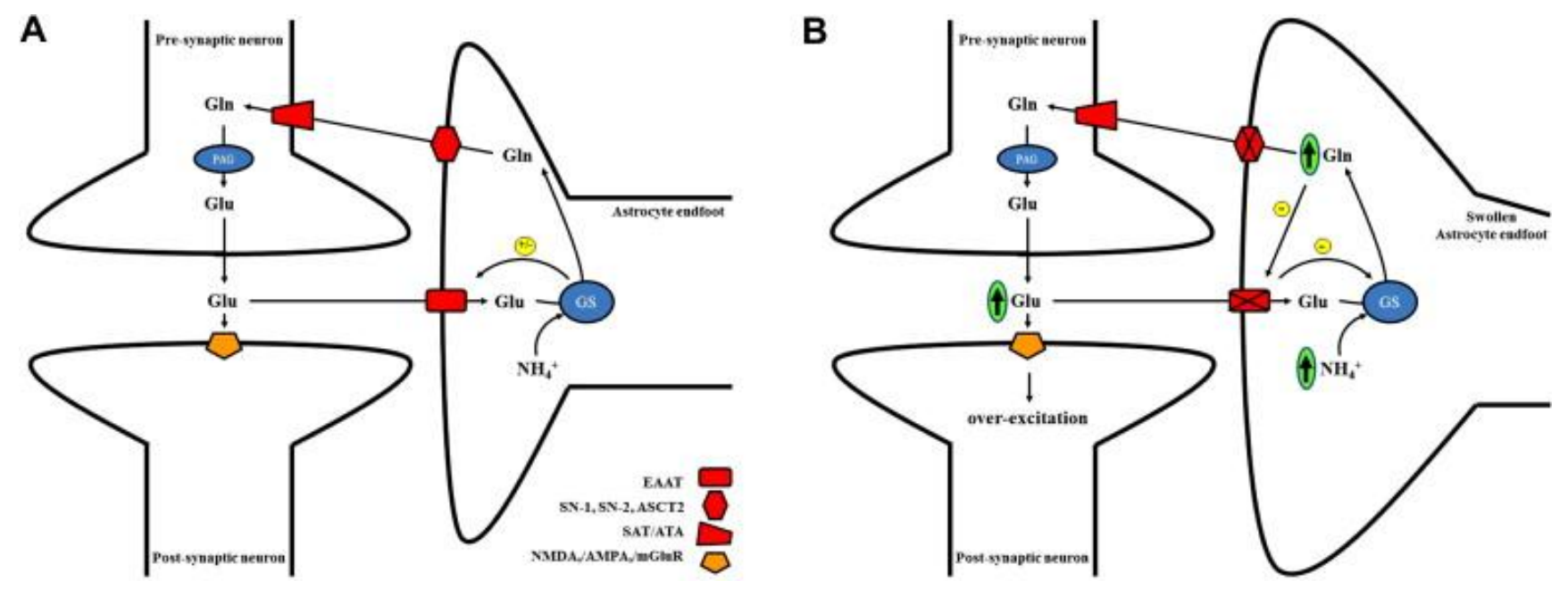

Fig. 4. Glutamate-glutamine metabolic cycle between astrocytes and neurons. (A) Under physiological conditions, glutamate $(\mathrm{Glu})$ is released into the synaptic space by presynaptic neurons inducing post-synaptic signaling through both ionotropic and metabotropic glutamate receptors (NMDA, AMPA, mGluR, $\oslash$ ). Glutamate is then cleared from the synaptic cleft by neighboring astrocytes through high affinity glutamate transporters (EAAT, $\square$ ). Transported glutamate is then amidated (using ammonia) to glutamine (Gln) through glutamine synthetase (GS). Glutamine is released into the extracellular space through astrocyte glutamine transporters (SN-1, SN-2 and ASCT2 $\square$ ) and shuttled to the neurons through neuronal glutamine transporters (SAT/ATA, $\square$ ) where it is converted back to glutamate via the action of phosphateactivated glutaminase (PAG); replenishing the neurotransmitter pool. Therefore, astrocytic glutamate uptake prevents glutamate accumulation in the synaptic cleft and over-excitation of the postsynaptic neuron receptors. (B) Proposed mechanism of alterations in the glutamate-glutamine cycle during hyperammonemic conditions: during conditions of elevated ammonia in the brain, since GS activity is coupled with glutamate uptake, an increase in intracellular glutamate (ammonia induced) will lead to an increase in osmotic pressure, water uptake and glutamine production. Inhibition of glutamine release from astrocytes (down-regulation of astrocyte glutamine transporters) will also contribute to astrocyte swelling. Furthermore, accumulated intracellular glutamine can feedback and inhibit glutamate uptake in astrocytes, resulting in a decrease in GS activity. Consequently, a decrease in glutamate clearance from astrocytes will lead to an increase in extracellular glutamate, over-excitation of the postsynaptic neuron receptors and development of HE.

During hyperammonemic conditions, an accumulation of glutamine in the astrocyte is observed and is believed to be an important osmotic contribution to astrocyte swelling (Brusilow and Traystman, 1986). It has been shown that pre-treatment of cultured astrocytes with the irreversible GS inhibitor, methionine sulfoximine (MSO), result in an attenuation in the increase in ammonia-induced glutamine and swelling (Norenberg and Bender, 1994). Similar results have been observed following ammonia-infusion in portacaval shunted rats pre-treated with MSO (Master et al., 1999 and Willard-Mack et al., 1996). However, following ammonia-lowering treatments, which are beneficial in attenuating brain edema and the onset of coma in animal models of ALF, a decrease in high cerebral glutamine levels was not observed (Ytrebø et al.,

2009 and Zwingmann et al., 2004). These studies suggest that in the setting of ALF, brain glutamine levels do not correlate with astrocyte swelling and brain edema. The beneficial effect of MSO as a treatment, as opposed to pre-treatment, needs thus to be further investigated.

It is important to note that an increase in astrocytic glutamine produced from intracellular-derived astrocytic glutamate will not induce osmotic changes. Namely, for the astrocyte to become hypertonic, extracellular osmolar molecules must enter the cell. GS activity is coupled with glutamate transport in astrocytes, since a significant upregulation of GS was shown to enhance glutamate uptake (Zou et al., 2010). Furthermore, inhibition of glutamate uptake leads to GS down-regulation (Ishikawa et al., 2011). Therefore, under high ammonia conditions in the brain, it is speculated that an increase in astrocytic glutamate uptake due to GS activity will induce osmotic changes and cause an influx of water. In turn, an increase in intracellular glutamine production will develop (Fig. 4B). This suggests that the key element in the development of brain edema is primarily glutamate uptake (Butterworth, 1997). It has been shown that cultured astrocytes exposed to glutamate

Bosoi, C.R. \& Rose, C.F., 2013. Brain edema in acute liver failure and chronic liver disease: Similarities and differences. Neurochemistry International, 62(4), p.446-457. 
causes swelling (Schneider et al., 1992). On the other hand, glutamine release into the extracellular space would help reduce the osmotic gradient between the astrocyte and the extracellular space, and thus decrease the degree of swelling. The downregulation of astrocytic glutamine transporters would then lead to an accumulation of glutamine (glutamine trapping), rendering the cell hypertonic and, therefore, contributing to cell swelling (Fig 4B). Based on ALF rat studies, there is evidence depicting that astrocytic glutamine transporters SN-2 are down-regulated, while SN-1 remained unchanged (Desjardins et al., 2012). However, since SN-1 and ASCT2, and not SN-2, are considered to be the main astrocytic transporters for glutamine, evidence depicting a down-regulation of these astrocytic transporters in the setting of brain edema in liver failure is yet to be confirmed.

An increase in extracellular glutamate has been documented to be associated with severe HE (Michalak et al., 1996, Oria et al., 2012, Rose et al., 2007 and Tofteng et al., 2002), and has been described to occur as a result of decreased mRNA and protein expression of astrocytic glutamate transporters (Desjardins et al., 2001, Knecht et al., 1997, Norenberg et al., 1997 and Suárez et al., 2000). Subsequently, this is accompanied by a decrease in GS activity, but the continuous presence of high glutamine levels (Desjardins et al., 1999 and Rao et al., 2005). Interestingly, the above observations are independent of ammonia toxicity since Mort and colleagues have shown, using electrophysiology techniques, ammonia stimulates glutamate uptake in astrocytes (Mort et al., 2001). Therefore, it is possible, as a defense mechanism, that upon swelling of the astrocyte (ammonia-induced glutamate uptake and glutamine formation/accumulation), the astrocyte shuts down (downregulates) the transport of glutamate into the cell to avoid further intracellular hypertonicity and cell swelling. This in turn, will consequently lead to an increase in extracellular glutamate causing hyperexcitability and contributing to severe $\mathrm{HE}$ (Oria et al., 2012 and Rose et al., 2007) (Fig. 4B). What remains to be determined is the temporal resolution of the underlying mechanism associated with the development of astrocyte swelling/brain edema.

Moreover, it has recently been suggested that glutamine induces astrocyte swelling and brain edema through a non-osmotic effect (reviewed by Albrecht et al. (Albrecht et al., 2010)). Here, it has been demonstrated, in vitro, that glutamine induces an opening of the mitochondrial transition pore and oxidative stress (Jayakumar et al., 2004 and Ziemińska et al., 2000). This has been supported in vivo (ALF rats) since the inhibition of the mitochondrial transport of glutamine attenuated oxidative stress, blocked the mitochondrial transition pore and prevented brain edema ( Rama Rao et al., 2010). Albrecht and Norenberg have proposed that the mitochondrial toxic effect of glutamine is due to its increased hydrolysis by glutaminase, resulting in ammonia liberation. This has been defined as the "Trojan horse" theory ( Albrecht and Norenberg, 2006).

To conclude, glutamate uptake is more pertinent to astrocyte swelling than an increase in intracellular glutamine per se. Nevertheless, glutamine "accumulation" has an important impact (both a metabolic and osmotic effect) on brain edema in ALF. However, the relationship between astrocytic glutamate and glutamine in the setting of CLD remains to be determined.

\subsection{Lactate}

Lactate is another pathogenic factor involved in the development of HE (Rose, 2010). It is important to note that lactate is no longer considered only a product of anaerobic glycolysis but is also a metabolite used by neurons as an energetic substrate (Pellerin and Magistretti, 2011). Lactate is produced from pyruvate by both astrocytes and neurons via the action of lactate dehydrogenase (LDH). However, astrocytes have been shown to be much more glycolytic than neurons, and thus produce large amounts of lactate via LDH-5 (astrocytic isoform), which is then expelled into the extracellular space through monocarboxylate transporters 1 and 4 (Pierre and Pellerin, 2005). Lactate can then be taken up by neurons via monocarboxylate transporters 2, and used as an energy substrate entering the tricarboxylic acid cycle through its conversion into pyruvate by neuronal LDH-1. This cycle constitutes the astrocyte-neuron lactate shuttle (Pellerin and Magistretti, 2011). During conditions of hyperammonemia, an increase in cerebral lactate is consistently found (Hawkins et al., 1973 and Rose et al., 2007) and is believed to be a consequence of a reduction in oxidative metabolism and impaired energy metabolism, since ammonia has shown to cause a direct inhibition of $\alpha$-ketoglutarate dehydrogenase (Lai and Cooper, 1986). However, high-energy phosphate levels are unaltered and preserved in the brain in both ALF and CLD animal models (Bates et al., 1989, Holmin et al., 1974 and Mans et al., 1994). Therefore, in the development of HE, increased brain lactate levels reflect energy impairment (dysregulations in lactate shuttle), as opposed to energy failure (a decrease in ATP).

Bosoi, C.R. \& Rose, C.F., 2013. Brain edema in acute liver failure and chronic liver disease: Similarities and differences. Neurochemistry International, 62(4), p.446-457. 
The role of lactate in astrocyte swelling has been well described in vitro ( Staub et al., 1990) as well as in animal models of ALF ( Chatauret et al., 2003, Chavarria et al., 2010, Sen et al., 2006 and Zwingmann et al., 2003). In ALF rats, induced by liver-devascularization, an increase in brain lactate was found at coma stages with brain edema, along with an increase in de novo lactate synthesis from glucose ( Zwingmann et al., 2003). Moreover, attenuation in elevated brain lactate was achieved in combination with a diminution in brain edema, following different therapeutic interventions (hypothermia and MARS) ( Chatauret et al., 2003 and Rose et al., 2007). In patients with ALF, an increase in extracellular brain lactate was found to correlate with ICP ( Tofteng et al., 2002). To date, no studies have specifically investigated the effect of ammonia toxicity on the astrocyte-neuron lactate shuttle. However, anecdotal evidence exists: an increase in LDH activity has been shown in ALF pigs, which lead to increased lactate but, interestingly, both LDH-1 and LDH-5 activities remained increased following MARS treatment, even though a reduction in extracellular lactate was demonstrated ( Rose et al., 2007). In the latter, the authors proposed that decreased extracellular lactate may be due to an increase in utilization by neurons, following a reduction in ammonia levels with MARS.

It has been speculated that an increase in the production of lactate in the brain leads to an osmotic increase in water, thus contributing to brain edema (Preuss, 2012). However, lactate metabolism, including the regulation of the astrocyte-neuron lactate shuttle and intracellular astrocyte lactate homeostasis, in the pathogenesis of brain edema in both CLD and ALF remains to be investigated.

\subsection{Water channels}

Aquaporins (Aqp) are transmembrane proteins that selectively conduct water in and out of the cell. So far, 13 isoforms have been identified, many of which are present in the brain. In particular, Aqp-4 has demonstrated to be highly expressed in astrocytes compared to neurons (Nielsen et al., 1997 and Rash et al., 1998), and has been proven to play a role in the pathogenesis of brain edema in several cerebral diseases: trauma (Donkin and Vink, 2010), brain tumors (Nico and Ribatti, 2011) and cerebrovascular disease (Badaut et al., 2011). Moreover, Aqp function is coupled with ion channels in order to maintain ionic homeostasis, especially $\mathrm{K}^{+}$(Nagelhus et al., 1999 and Rao et al., 2011). Since $\mathrm{K}^{+}$channels can transport ammonia (NH4+) as explained above, together these mechanisms could contribute to brain edema. However, Aqp role in the pathogenesis of brain edema in HE remains controversial. An increase of Aqp-4 expression has been found in ammoniainduced swelling of cultured astrocytes (Rama Rao et al., 2003). Furthermore, an increase in expression of Aqp-4 in the brain, in association with brain edema, has been demonstrated in both ALF mice (Eefsen et al., 2010) and cirrhotic rats (Wright et al., 2010). However, on the contrary, the presence of brain edema was not related with an increase in brain Aqp-4 in either galactosamine treated or chronic hyperammonemic (induced by hyperammonemic diet) rats (Wright et al., 2010). Therefore, inconsistent results relating the upregulation of Aqp-4 with brain edema dictate future investigations. The latter are warranted in order to clarify the role of Aqp-4 and other Aqp isoforms in the pathogenesis of brain edema in both ALF and CLD.

\subsection{Inflammation}

Cerebral inflammation has been demonstrated to contribute to the induction of HE (reviewed by Butterworth (Butterworth, 2011)), and systemic inflammation is believed to exacerbate the neurotoxic effects of ammonia (Shawcross et al., 2004). In ALF patients, serum proinflammatory cytokines have been shown to be correlated with brain edema (Gupta et al., 2010), as well as increased ICP (Jalan et al., 2004b). Similar results have been documented in ALF (hepatic devascularized) rats; moreover, it was found that brain-derived proinflammatory mechanisms contributed to brain edema. A beneficial effect of hypothermia and antibiotic treatment in attenuating brain edema in ALF rats was accompanied with a decrease in both serum and cerebral cytokines (Jiang et al., 2009a and Jiang et al., 2009b). More specifically, suppressed IL-1 and TNF $\alpha$ expression prevented the development of brain edema in ALF (azoxymethane-induced) IL-1 and TNF $\alpha$ knock-out mice (Bémeur et al., 2010).

In CLD, inflammation has also been linked to the development of brain edema. Montoliu and colleagues found that serum proinflammatory cytokines Il-6 and IL-18 are higher in cirrhotic patients with MHE, compared to cirrhotic patients without HE (Montoliu et al., 2009). Brain edema was not evaluated within the studied group of patients; however, other studies have previously demonstrated that brain edema is associated with MHE (Córdoba et al., 2001, Rovira et al., 2002 and Sugimoto et al., 2008). Moreover, lipopolysaccharide (LPS) injection in BDL rats led to the appearance of brain edema, accompanied 
by an increase in serum and brain proinflammatory cytokines (Wright et al., 2007). In vitro studies have demonstrated that pro-inflammatory cytokine IL-1 $\beta$ affects astrocytic genes involved in cell volume regulation, including Aqp-4 ( Chastre et al., 2010). This, in turn, could render the astrocyte vulnerable to swelling. Furthermore, inflammatory mediators are known to increase BBB permeability and contribute to brain edema ( Abbott, 2000).

\subsection{Oxidative stress}

The effects of oxidative stress and reactive oxygen species (ROS) on biological systems are numerous. ROS induce cellular damage by affecting DNA and RNA expression, proteins and proper function of transporters, channels, receptors and enzymes, lipids and membrane stability. There is ample evidence stating that oxidative stress plays a role in the pathogenesis of brain edema in HE. Cultured astrocytes acutely treated with ammonia concentrations $(>1 \mathrm{mM})$ display cell swelling and production of ROS (Murthy et al., 2001), which are attenuated with antioxidant treatments (Jayakumar et al., 2006). This suggests that ammonia-induced astrocyte swelling is linked to the generation of ROS. This is supported by in vivo studies, where the presence of brain edema in ALF rats (induced-by liver devascularisation) is associated with hyperammonemia (>1 mM) and cerebral ROS ( Jiang et al., 2009c). However, in the setting of CLD, systemic oxidative stress, rather than cerebral oxidative stress, plays a major role in the onset of brain edema. Our group recently demonstrated, in six-week BDL rats, that brain edema develops in the presence of systemic, and not cerebral, oxidative stress ( Bosoi et al., 2012). This systemic phenomenon was confirmed as the attenuation of systemic oxidative stress using allopurinol (xanthine oxidase inhibitor) led to a reduction in brain edema ( Bosoi et al., 2012). In the same animal model, our group demonstrated that blood ammonia and oxidative stress are independent factors, and are synergistically implicated in the development of brain edema ( Bosoi et al., 2012). Here, BDL rats treated with the oral carbon microspheres (ammonia adsorbent) AST-120 showed an attenuation of ammonia and brain edema, but systemic oxidative stress remained present ( Bosoi et al., 2011). These findings have been supported clinically as the oxidative marker 3-nitrotyrosine was found to be increased in the plasma of patients with MHE compared to cirrhotic patients without MHE, with both groups of patients having similar levels of hyperammonemia ( Montoliu et al., 2011). These studies suggest a synergistic effect between systemic oxidative stress and hyperammonemia in the pathogenesis of brain edema and HE during CLD.

There is increasing evidence that ammonia-induced oxidative stress is concentration-dependent. It has been shown that ammonia applied to cultured astrocytes, at concentrations of 100 and $200 \mu \mathrm{M}$, does not induce oxidative stress, while concentrations of ammonia $>500 \mu \mathrm{M}$ result in ROS generation (Görg et al., 2008 and Mehrotra and Trigun, 2012). In vivo, blood and brain ammonia levels are significantly lower in CLD rats than in ALF ( $<250 \mu \mathrm{M}$ in CLD compared to $>800 \mu \mathrm{M}$ in ALF, ( Bosoi et al., 2012 and Jiang et al., 2009c)); however, cerebral oxidative stress was observed only in ALF rats. In support of this, in PCA rats, a model of chronic hyperammonemia with ammonia levels $<250 \mu \mathrm{M}$, no signs of oxidative stress were observed in the brain ( Bosoi et al., 2012). This suggests that a threshold of ammonia (i.e. $>500 \mu \mathrm{M}$ ) is needed in order to induce oxidative stress in the brain. However, the acuteness in the rise of ammonia must also be considered as an important factor.

The presence of cerebral oxidative stress in ALF occurs in association with severe HE (pre-coma and coma stages). Recently, cerebral oxidative stress markers were measured in the post-mortem cortical brain tissue of cirrhotic patients who died with overt HE (grade >3) (Görg et al., 2010). This suggests that cerebral oxidative stress may play an important role in the development of severe (overt) HE (Bosoi and Rose, 2012).

\section{ROLE OF BRAIN EDEMA IN HE}

In ALF, intracranial hypertension is the primary cause to brain stem herniation and death. Brain edema undoubtedly is linked to a rise of cerebral water in ALF, however aside from its physical contribution to brain volume and ICP, its role in the severe deterioration of neurological function remains unresolved. Brain edema in CLD patients is associated with MHE; not clinically obvious deterioration of neurological function. However, since patients with MHE have an 4 -fold increased risk of developing overt HE (Hartmann et al., 2000), brain edema may be a predisposing factor implicated in this risk.

It is believed that small increases in astrocyte water content may have important functional consequences, including neuronal dysfunction, despite the absence of intracranial hypertension (Häussinger et al., 2000). Termed "low-grade"

Bosoi, C.R. \& Rose, C.F., 2013. Brain edema in acute liver failure and chronic liver disease: Similarities and differences. Neurochemistry International, 62(4), p.446-457. 
edema, this suggests that HE represents a clinical manifestation of astrocyte swelling. However, in BDL and PCA rats, both well described models of HE (Butterworth et al., 2009), brain edema is only present in BDL rats. This raises questions regarding the role of brain edema in the neurological alterations related to HE. The results of many studies have suggested brain edema is not related to HE. Oria and colleagues demonstrated that upon decreasing brain water content in the cortex and brain stem in ALF following mannitol treatment, motor tract function did not improve (Oria et al., 2010). However, in this study, the authors only evaluated brain water in the cortex and brain stem; therefore, it is possible that the regions implicated in the modulation of the motor tract function (red nucleus, substantia nigra, basal ganglia) were not edematous and therefore would not respond to mannitol treatment. Moreover, PCA rats, following ammonia challenge, develop severe alterations of the motor tract function, without the development of brain edema (Oria et al., 2010). In a study by Wright and colleagues, both BDL and sham-operated controls challenged with LPS lead to brain edema; however, only BDL rats presented alterations of neurological status (Wright et al., 2007). Here, this indicates brain edema may play a predisposing role in the pathogenesis of HE. Furthermore, in cirrhotic patients with overt HE, brain edema still persisted for 5 days following clinical resolution of HE (Poveda et al., 2010). However, since the resolution of HE in these patients was defined as regression of clinically evident signs (overt) of HE, it is possible that these patients improved to MHE (for which they had not been tested) and therefore were not HE-free.

On the contrary, many studies have demonstrated brain edema is implicated in the pathogenesis of HE. Our group demonstrated that both ammonia lowering and antioxidant treatments in BDL rats attenuate the development of brain edema, along with amelioration of neurological status (Bosoi et al., 2012 and Bosoi et al., 2011). Furthermore, several studies in cirrhotic patients have showed a positive correlation between brain edema (evaluated by different magnetic resonance techniques) and scoring in neuropsychological tests (Kumar et al., 2008 and Sugimoto et al., 2008). In addition, following liver transplantation in patients with MHE, a decrease in brain edema was associated with an improvement in cognitive function (Rovira et al., 2007).

Altogether, the role of brain edema, as a neuropathological feature of $\mathrm{HE}$ or a cause of HE, remains a controversial topic. It is speculated different degrees of astrocyte swelling/brain edema may inflict differential effects (physical stress as well as metabolic alterations) on cerebral function. On the contrary, brain edema may not have a direct metabolic effect of cerebral function but alternatively, could be a predisposing factor in the development of HE. Similarly, brain edema may act synergistically with other pathogenic factors and induce HE.

\section{CONCLUSION}

In summary, brain edema is present in both ALF and CLD, and a combination of multiple factors can lead to its development (vasogenic or cytotoxic). In ALF, a rapid development of brain edema contributes to an increase in ICP, which physically stresses the brain and causes sudden neurological deterioration. However, in CLD, during which an increase in ICP is rarely observed, the role of brain edema in the pathogenesis of HE remains elusive; brain edema (astrocyte swelling) can lead to dysregulated astrocyte-neuronal communication and, hence, impaired cerebral function, or simply brain edema, may predispose the brain to an increased risk of developing MHE. Different mechanisms of brain edema (vasogenic and cytotoxic edema, including a combination of the two) between ALF and CLD may be responsible for the numerous pathophysiological mechanisms causing HE.

Furthermore, the implication of different regions (white and gray matter) of the brain may be accountable for the variety of symptoms observed in HE; possibly a result of distinctive types of astrocytes which may react differently (susceptible) to pathogenic factors like ammonia, glutamine, lactate, water channels, inflammation or oxidative stress. Furthermore, these factors may reach different concentrations or appear in combination with others, causing an array of HE symptoms. Therefore, in the future, types of HE should not only be defined by the underlying type of liver failure, but also by the neurological symptomatology.

Bosoi, C.R. \& Rose, C.F., 2013. Brain edema in acute liver failure and chronic liver disease: Similarities and differences. Neurochemistry International, 62(4), p.446-457. 


\section{REFERENCES}

Abbott, N.J., 2000. Inflammatory mediators and modulation of blood-brain barrier permeability. Cell. Mol. Neurobiol. 20, $131-147$.

Aickin, C.C., Deisz, R.A., Lux, H.D., 1982. Ammonium action on post-synaptic inhibition in crayfish neurones: implications for the mechanism of chloride extrusion. J. Physiol. (Lond.) 329, 319-339.

Albrecht, J., Norenberg, M.D., 2006. Glutamine: a Trojan horse in ammonia neurotoxicity. Hepatology 44, $788-794$.

Albrecht, J., Zielińska, M., Norenberg, M.D., 2010. Glutamine as a mediator of ammonia neurotoxicity: A critical appraisal. Biochem. Pharmacol. 80, 1303-1308.

Alexander, B., Li, X., Benjamin, I.S., Segal, M.B., Sherwood, R., Preston, J.E., 2000. A quantitative evaluation of the permeability of the blood brain barrier of portacaval shunted rats. Metab Brain Dis 15, 93-103.

Almdal, T., Schroeder, T., Ranek, L., 1989. Cerebral blood flow and liver function in patients with encephalopathy due to acute and chronic liver diseases. Scand. J. Gastroenterol. 24, 299-303.

Amodio, P., 2009. Health related quality of life and minimal hepatic encephalopathy. It is time to insert "quality" in health care. J. Gastroenterol. Hepatol. 24, 329-330.

Amodio, P., Biancardi, A., Montagnese, S., Angeli, P., Iannizzi, P., Cillo, U., D’Amico, D., Gatta, A., 2007. Neurological complications after orthotopic liver transplantation. Dig Liver Dis 39, 740-747.

Badaut, J., Ashwal, S., Obenaus, A., 2011. Aquaporins in cerebrovascular disease: a target for treatment of brain edema? Cerebrovasc. Dis. 31, 521-531.

Bates, T.E., Williams, S.R., Kauppinen, R.A., Gadian, D.G., 1989. Observation of cerebral metabolites in an animal model of a cute liver failure in vivo: a $1 \mathrm{H}$ and 31P nuclear magnetic resonance study. J. Neurochem. 53, 102-110.

Bémeur, C., Qu, H., Desjardins, P., Butterworth, R.F., 2010. IL-1 or TNF receptor gene deletion delays onset of encephalopathy and attenuates brain edema in experimental acute liver failure. Neurochem. Int. 56, 213-215.

Bernal, W., Hall, C., Karvellas, C.J., Auzinger, G., Sizer, E., Wendon, J., 2007. Arterial ammonia and clinical risk factors for encephalopathy and intracranial hypertension in acute liver failure. Hepatology 46, 1844-1852.

Bertrand, E., Lewandowska, E., Szpak, G.M., Hoogenraad, T., Blaauwgers, H.G., Członkowska, A., Dymecki, J., 2001. Neuropathological analysis of pathological forms of astroglia in Wilson's disease. Folia Neuropathol 39, 73-79.

Bignami, A., Dahl, D., 1974. Astrocyte-specific protein and neuroglial differentiation. An immunofluorescence study with antibodies to the glial fibrillary acidic protein. J. Comp. Neurol. 153, 27-38.

Bosoi, C.R., Parent-Robitaille, C., Anderson, K., Tremblay, M., Rose, C.F., 2011. AST-120 (spherical carbon adsorbent) lowers ammonia levels and attenuates brain edema in bile duct-ligated rats. Hepatology 53, 1995-2002.

Bosoi, C.R., Rose, C.F., 2009. Identifying the direct effects of ammonia on the brain. Metab Brain Dis 24, 95-102.

Bosoi, C.R., Yang, X., Huynh, J., Parent-Robitaille, C., Jiang, W., Tremblay, M., Rose, C.F., 2012. Systemic oxidative stress is implicated in the pathogenesis of brain edema in rats with chronic liver failure. Free Radic. Biol. Med. 52, 1228-1235.

Brusilow, S.W., Traystman, R., 1986. Hepatic encephalopathy. N. Engl. J. Med. 314, 786-787; author reply 787.

Burra, P., Senzolo, M., Pizzolato, G., Ermani, M., Chierichetti, F., Bassanello, M., Naccarato, R., Dam, M., 2004. Does liver-disease aetiology have a role in cerebral blood-flow alterations in liver cirrhosis? Eur J Gastroenterol Hepatol 16, 885-890.

Butterworth, R.F., 1997. Hepatic encephalopathy and brain edema in acute hepatic failure: does glutamate play a role? Hepatology 25, 1032-1034.

Butterworth, R.F., 2007. Neuronal cell death in hepatic encephalopathy. Metab Brain Dis 22, 309-320.

Butterworth, R.F., 2011. Neuroinflammation in acute liver failure: Mechanisms and novel therapeutic targets. Neurochem. Int. 59, 830-836.

Butterworth, R.F., Norenberg, M.D., Felipo, V., Ferenci, P., Albrecht, J., Blei, A.T., 2009. Experimental models of hepatic encephalopathy: ISHEN guidelines. Liver Int. 29, 783-788.

Cauli, O., López-Larrubia, P., Rodrigo, R., Agusti, A., Boix, J., Nieto-Charques, L., Cerdán, S., Felipo, V., 2011. Brain region-selective mechanisms contribute to the progression of cerebral alterations in acute liver failure in rats. Gastroenterology 140, 638-645.

Chastre, A., Jiang, W., Desjardins, P., Butterworth, R.F., 2010. Ammonia and proinflammatory cytokines modify expression of genes coding for astrocytic proteins implicated in brain edema in acute liver failure. Metab Brain Dis 25, 17-21.

Chatauret, N., Zwingmann, C., Rose, C., Leibfritz, D., Butterworth, R.F., 2003. Effects of hypothermia on brain glucose metabolism in acute liver failure: a H/C-nuclear magnetic resonance study. Gastroenterology 125, 815-824.

Chaudhry, F.A., Reimer, R.J., Krizaj, D., Barber, D., Storm-Mathisen, J., Copenhagen, D.R., Edwards, R.H., 1999. Molecular analysis of system $\mathrm{N}$ suggests novel physiological roles in nitrogen metabolism and synaptic transmission. Cell 99, 769-780.

Chavarria, L., Alonso, J., García-Martínez, R., Aymerich, F.X., Huerga, E., Jacas, C., Vargas, V., Cordoba, J., Rovira, A., 2011. Biexponential analysis of diffusion-tensor imaging of the brain in patients with cirrhosis before and after liver transplantation. AJNR Am J Neuroradiol 32, 1510-1517.

Chavarria, L., Oria, M., Romero-Gimenez, J., Alonso, J., Lope-Piedrafita, S., Cordoba, J., 2010. Diffusion tensor imaging supports the cytotoxic origin of brain edema in a rat model of acute liver failure. Gastroenterology 138, 1566-1573.

Chen, F., Ohashi, N., Li, W., Eckman, C., Nguyen, J.H., 2009. Disruptions of occludin and claudin-5 in brain endothelial cells in vitro and in brains of mice with acute liver failure. Hepatology 50, 1914-1923.

Clemmesen, J.O., Larsen, F.S., Kondrup, J., Hansen, B.A., Ott, P., 1999. Cerebral herniation in patients with acute liver failure is correlated with arterial ammonia concentration. Hepatology 29, 648-653.

Bosoi, C.R. \& Rose, C.F., 2013. Brain edema in acute liver failure and chronic liver disease: Similarities and differences. Neurochemistry International, 62(4), p.446-457. 
Conn, H.O., Leevy, C.M., Vlahcevic, Z.R., Rodgers, J.B., Maddrey, W.C., Seeff, L., Levy, L.L., 1977. Comparison of lactulose and neomycin in the treatment of chronic portal-systemic encephalopathy. A double blind controlled trial. Gastroenterology 72 , 573-583.

Cooper, A.J., 2001. Role of glutamine in cerebral nitrogen metabolism and ammonia neurotoxicity. Ment Retard Dev Disabil Res Rev 7, 280-286.

Cooper, A.J., Plum, F., 1987. Biochemistry and physiology of brain ammonia. Physiol. Rev. 67, 440-519.

Córdoba, J., Alonso, J., Rovira, A., Jacas, C., Sanpedro, F., Castells, L., Vargas, V., Margarit, C., Kulisewsky, J., Esteban, R., Guardia, J., 2001. The development of low-grade cerebral edema in cirrhosis is supported by the evolution of (1)H-magnetic resonance abnormalities after liver transplantation. J. Hepatol. 35, 598-604.

Córdoba, J., Raguer, N., Flavià, M., Vargas, V., Jacas, C., Alonso, J., Rovira, A., 2003. T2 hyperintensity along the cortico-spinal tract in cirrhosis relates to functional abnormalities. Hepatology 38, 1026-1033.

Cubelos, B., González-González, I.M., Giménez, C., Zafra, F., 2005. Amino acid transporter SNAT5 localizes to glial cells in the rat brain. Glia 49, 230-244.

Dam, M., Burra, P., Tedeschi, U., Cagnin, A., Chierichetti, F., Ermani, M., Ferlin, G., Naccarato, R., Pizzolato, G., 1998. Regional cerebral blood flow changes in patients with cirrhosis assessed with 99mTc-HM-PAO single-photon emission computed tomography: effect of liver transplantation. Journal of Hepatology 29, 78-84.

Davies, N.A., Wright, G., Ytrebø, L.M., Stadlbauer, V., Fuskevåg, O.-M., Zwingmann, C., Davies, D.C., Habtesion, A., Hodges, S.J., Jalan, R., 2009. L-ornithine and phenylacetate synergistically produce sustained reduction in ammonia and brain water in cirrhotic rats. Hepatology 50, 155-164.

Desjardins, P., Bélanger, M., Butterworth, R.F., 2001. Alterations in expression of genes coding for key astrocytic proteins in acute liver failure. J. Neurosci. Res. 66, 967-971.

Desjardins, P., Du, T., Jiang, W., Peng, L., Butterworth, R.F., 2012. Pathogenesis of hepatic encephalopathy and brain edema in acute liver failure: Role of glutamine redefined. Neurochem. Int. 60, 690-696.

Desjardins, P., Rao, K.V., Michalak, A., Rose, C., Butterworth, R.F., 1999. Effect of portacaval anastomosis on glutamine synthetase protein and gene expression in brain, liver and skeletal muscle. Metab Brain Dis 14, 273-280.

Dixit, V., Chang, T.M., 1990. Brain edema and the blood brain barrier in galactosamine-induced fulminant hepatic failure rats. An animal model for evaluation of liver support systems. ASAIO Trans 36, 21-27.

Dolińska, M., Zabłocka, B., Sonnewald, U., Albrecht, J., 2004. Glutamine uptake and expression of mRNA's of glutamine transporting proteins in mouse cerebellar and cerebral cortical astrocytes and neurons. Neurochem. Int. 44, 75-81.

Donkin, J.J., Vink, R., 2010. Mechanisms of cerebral edema in traumatic brain injury: therapeutic developments. Curr. Opin. Neurol. 23, 293-299.

Eefsen, M., Jelnes, P., Schmidt, L.E., Vainer, B., Bisgaard, H.C., Larsen, F.S., 2010. Brain expression of the water channels aquaporin1 and -4 in mice with acute liver injury, hyperammonemia and brain edema. Metab Brain Dis 25, 315-323.

Fauci, Anthony, Braunwald, Eugene, Kasper, Dennis, Hauser, Stephen, Longo, Dan, Jameson, J., Loscalzo, Joseph, 2011. Harrison's Principles of Internal Medicine, 18th ed. McGraw-Hill, New York.

Ferenci, P., Lockwood, A., Mullen, K., Tarter, R., Weissenborn, K., Blei, A.T., 2002. Hepatic encephalopathy--definition, nomenclature, diagnosis, and quantification: final report of the working party at the 11th World Congresses of Gastroenterology, Vienna, 1998. Hepatology 35, 716-721.

Fleming, K.M., Aithal, G.P., Card, T.R., West, J., 2012. All-cause mortality in people with cirrhosis compared with the general population: a population-based cohort study. Liver International 32, 79-84.

Frederick, R.T., 2012. Extent of reversibility of hepatic encephalopathy following liver transplantation. Clin Liver Dis 16, 147-158.

Fridman, V., Galetta, S.L., Pruitt, A.A., Levine, J.M., 2009. MRI findings associated with acute liver failure. Neurology 72, $2130-2131$.

Garcia-Martinez, R., Rovira, A., Alonso, J., Jacas, C., Simón-Talero, M., Chavarria, L., Vargas, V., Córdoba, J., 2011. Hepatic encephalopathy is associated with posttransplant cognitive function and brain volume. Liver Transpl. 17, 38-46.

Gegelashvili, M., Rodriguez-Kern, A., Sung, L., Shimamoto, K., Gegelashvili, G., 2007. Glutamate transporter GLAST/EAAT1 directs cell surface expression of FXYD2/gamma subunit of Na, K-ATPase in human fetal astrocytes. Neurochem. Int. 50, 916-920.

Görg, B., Qvartskhava, N., Bidmon, H.-J., Palomero-Gallagher, N., Kircheis, G., Zilles, K., Häussinger, D., 2010. Oxidative stress markers in the brain of patients with cirrhosis and hepatic encephalopathy. Hepatology 52, 256-265.

Görg, B., Qvartskhava, N., Keitel, V., Bidmon, H.J., Selbach, O., Schliess, F., Häussinger, D., 2008. Ammonia induces RNA oxidation in cultured astrocytes and brain in vivo. Hepatology 48, 567-579.

Guarino, M., Benito-Leon, J., Decruyenaere, J., Schmutzhard, E., Weissenborn, K., Stracciari, A., 2006. EFNS guidelines on management of neurological problems in liver transplantation. Eur. J. Neurol. 13, 2-9.

Gullans, S.R., Verbalis, J.G., 1993. Control of brain volume during hyperosmolar and hypoosmolar conditions. Annu. Rev. Med. 44, 289-301.

Gupta, R.K., Yadav, S.K., Rangan, M., Rathore, R.K.S., Thomas, M.A., Prasad, K.N., Pandey, C.M., Saraswat, V.A., 2010. Serum proinflammatory cytokines correlate with diffusion tensor imaging derived metrics and $1 \mathrm{H}-\mathrm{MR}$ spectroscopy in patients with acute liver failure. Metab Brain Dis 25, 355-361.

Hartmann, I.J., Groeneweg, M., Quero, J.C., Beijeman, S.J., De Man, R.A., Hop, W.C., Schalm, S.W., 2000. The prognostic significance of subclinical hepatic encephalopathy. Am. J. Gastroenterol. 95, 2029-2034.

Häussinger, D., 2006. Low grade cerebral edema and the pathogenesis of hepatic encephalopathy in cirrhosis. Hepatology 43, 1187-1190.

Häussinger, D., Kircheis, G., Fischer, R., Schliess, F., Dahl, S. vom, 2000. Hepatic encephalopathy in chronic liver disease: a clinical manifestation of astrocyte swelling and low-grade cerebral edema? Journal of Hepatology 32, 1035-1038.

Bosoi, C.R. \& Rose, C.F., 2013. Brain edema in acute liver failure and chronic liver disease: Similarities and differences. Neurochemistry International, 62(4), p.446-457. 
Hawkins, R.A., Houghton, C.R., Williamson, D.H., 1973. Hepatic redox state and gluconeogenesis from lactate in vivo in the rat. Biochem. J. 132, 19-25.

He, Y., Li, G., Song, H., Luo, T., Gao, B., Xu, J., 2011. Partial pressure of NH3 in cirrhotic patients with and without hepatic encephalopathy. J Gastrointestin Liver Dis 20, 169-174.

Hedman, A.M., Van Haren, N.E.M., Schnack, H.G., Kahn, R.S., Hulshoff Pol, H.E., 2011. Human brain changes across the life span: A review of 56 longitudinal magnetic resonance imaging studies. Hum Brain Mapp.

Hirrlinger, P.G., Wurm, A., Hirrlinger, J., Bringmann, A., Reichenbach, A., 2008. Osmotic swelling characteristics of glial cells in the murine hippocampus, cerebellum, and retina in situ. J. Neurochem. 105, 1405-1417.

Hogstad, S., Svenneby, G., Torgner, I.A., Kvamme, E., Hertz, L., Schousboe, A., 1988. Glutaminase in neurons and astrocytes cultured from mouse brain: kinetic properties and effects of phosphate, glutamate, and ammonia. Neurochem. Res. 13, 383-388.

Holmin, T., Jóhannsson, H., Siesjö, B.K., 1974. Effects on cerebral energy state of arterial hypotension in rats with porta-caval anastomosis. Acta Physiol. Scand. 90, 345-357.

Horowitz, M.E., Schafer, D.F., Molnar, P., Jones, E.A., Blasberg, R.G., Patlak, C.S., Waggoner, J., Fenstermacher, J.D., 1983. Increased blood-brain transfer in a rabbit model of acute liver failure. Gastroenterology 84, 1003-1011.

Huynh, J., Bosoi, C.R., Parent-Robitaille, C., Tremblay, M., Rose, C.F., 2011. Na-K-Cl cotransporter is implicated in the pathogenesis of brain edema. J. Hepatol. 54, S249-S250.

Ishikawa, M., Yoshitomi, T., Zorumski, C.F., Izumi, Y., 2011. Downregulation of glutamine synthetase via GLAST suppression induces retinal axonal swelling in a rat ex vivo hydrostatic pressure model. Invest. Ophthalmol. Vis. Sci. 52, 6604-6616.

Iversen, P., Sørensen, M., Bak, L.K., Waagepetersen, H.S., Vafaee, M.S., Borghammer, P., Mouridsen, K., Jensen, S.B., Vilstrup, H., Schousboe, A., Ott, P., Gjedde, A., Keiding, S., 2009. Low Cerebral Oxygen Consumption and Blood Flow in Patients With Cirrhosis and an Acute Episode of Hepatic Encephalopathy. Gastroenterology 136, 863-871.

Iwasa, M., Matsumura, K., Kaito, M., Ikoma, J., Kobayashi, Y., Nakagawa, N., Watanabe, S., Takeda, K., Adachi, Y., 2000. Decrease of regional cerebral blood flow in liver cirrhosis. Eur J Gastroenterol Hepatol 12, 1001-1006.

Jalan, R., Olde Damink, S.W.M., Deutz, N.E.P., Hayes, P.C., Lee, A., 2004a. Moderate hypothermia in patients with acute liver failure and uncontrolled intracranial hypertension. Gastroenterology 127, 1338-1346.

Jalan, R., Olde Damink, S.W.M., Hayes, P.C., Deutz, N.E.P., Lee, A., 2004b. Pathogenesis of intracranial hypertension in acute liver failure: inflammation, ammonia and cerebral blood flow. J. Hepatol. 41, 613-620.

Jayakumar, A.R., Panickar, K.S., Murthy, C.R.K., Norenberg, M.D., 2006. Oxidative stress and mitogen-activated protein kinase phosphorylation mediate ammonia-induced cell swelling and glutamate uptake inhibition in cultured astrocytes. J. Neurosci. 26, 4774-4784.

Jayakumar, A.R., Rama Rao, K.V., Schousboe, A., Norenberg, M.D., 2004. Glutamine-induced free radical production in cultured astrocytes. Glia 46, 296-301.

Jayakumar, A.R., Tong, X.Y., Ospel, J., Norenberg, M.D., 2012. Role of cerebral endothelial cells in the astrocyte swelling and brain edema associated with acute hepatic encephalopathy. Neuroscience 218, 305-316.

Jiang, W., Desjardins, P., Butterworth, R.F., 2009a. Direct evidence for central proinflammatory mechanisms in rats with experimental acute liver failure: protective effect of hypothermia. J. Cereb. Blood Flow Metab. 29, 944-952.

Jiang, W., Desjardins, P., Butterworth, R.F., 2009b. Cerebral inflammation contributes to encephalopathy and brain edema in acute liver failure: protective effect of minocycline. J. Neurochem. 109, 485-493.

Jiang, W., Desjardins, P., Butterworth, R.F., 2009c. Hypothermia attenuates oxidative/nitrosative stress, encephalopathy and brain edema in acute (ischemic) liver failure. Neurochem. Int. 55, 124-128.

Kale, R.A., Gupta, R.K., Saraswat, V.A., Hasan, K.M., Trivedi, R., Mishra, A.M., Ranjan, P., Pandey, C.M., Narayana, P.A., 2006. Demonstration of interstitial cerebral edema with diffusion tensor MR imaging in type $C$ hepatic encephalopathy. Hepatology 43, 698-706.

Kato, M., Hughes, R.D., Keays, R.T., Williams, R., 1992. Electron microscopic study of brain capillaries in cerebral edema from fulminant hepatic failure. Hepatology 15, 1060-1066.

Kelly, T., Rose, C.R., 2010. Ammonium influx pathways into astrocytes and neurones of hippocampal slices. J. Neurochem. 115, 1123-1136.

Kimelberg, H.K., 2005. Astrocytic swelling in cerebral ischemia as a possible cause of injury and target for therapy. Glia 50, 389397.

Klatzo, I., 1967. Presidental address. Neuropathological aspects of brain edema. J. Neuropathol. Exp. Neurol. $26,1-14$.

Knecht, K., Michalak, A., Rose, C., Rothstein, J.D., Butterworth, R.F., 1997. Decreased glutamate transporter (GLT-1) expression in frontal cortex of rats with acute liver failure. Neurosci. Lett. 229, 201-203.

Kristiansen, R.G., Lindal, S., Myreng, K., Revhaug, A., Ytrebø, L.M., Rose, C.F., 2010. Neuropathological changes in the brain of pigs with acute liver failure. Scand. J. Gastroenterol. 45, 935-943.

Kumar, R., Gupta, R.K., Elderkin-Thompson, V., Huda, A., Sayre, J., Kirsch, C., Guze, B., Han, S., Thomas, M.A., 2008. Voxel-based diffusion tensor magnetic resonance imaging evaluation of low-grade hepatic encephalopathy. J Magn Reson Imaging 27, 1061-1068.

Kundra, A., Jain, A., Banga, A., Bajaj, G., Kar, P., 2005. Evaluation of plasma ammonia levels in patients with acute liver failure and chronic liver disease and its correlation with the severity of hepatic encephalopathy and clinical features of raised intracranial tension. Clin Biochem 38, 696-699.

Lai, J.C., Cooper, A.J., 1986. Brain alpha-ketoglutarate dehydrogenase complex: kinetic properties, regional distribution, and effects of inhibitors. J. Neurochem. 47, 1376-1386.

Bosoi, C.R. \& Rose, C.F., 2013. Brain edema in acute liver failure and chronic liver disease: Similarities and differences. Neurochemistry International, 62(4), p.446-457. 
Lang, F., Busch, G.L., Ritter, M., Völkl, H., Waldegger, S., Gulbins, E., Häussinger, D., 1998. Functional Significance of Cell Volume Regulatory Mechanisms. Physiol Rev 78, 247-306.

Larsen, F.S., Adel Hansen, B., Pott, F., Ejlersen, E., Secher, N.H., Paulson, O.B., Knudsen, G.M., 1996. Dissociated cerebral vasoparalysis in acute liver failure. A hypothesis of gradual cerebral hyperaemia. J. Hepatol. 25, 145-151.

Lee, W.M., 1993. Acute Liver Failure. New England Journal of Medicine 329, 1862-1872.

Lee, W.M., 2012. Acute liver failure. Semin Respir Crit Care Med 33, 36-45.

Lukaszevicz, A.-C., Sampaïo, N., Guégan, C., Benchoua, A., Couriaud, C., Chevalier, E., Sola, B., Lacombe, P., Onténiente, B., 2002. High sensitivity of protoplasmic cortical astroglia to focal ischemia. J. Cereb. Blood Flow Metab. 22, 289-298.

Lv, S., Song, H.-L., Zhou, Y., Li, L.-X., Cui, W., Wang, W., Liu, P., 2010. Tumour necrosis factor-alpha affects blood-brain barrier permeability and tight junction-associated occludin in acute liver failure. Liver Int. 30, 1198-1210.

Mans, A.M., DeJoseph, M.R., Hawkins, R.A., 1994. Metabolic abnormalities and grade of encephalopathy in acute hepatic failure. J. Neurochem. 63, 1829-1838.

Marmarou, A., Poll, W., Shulman, K., Bhagavan, H., 1978. A simple gravimetric technique for measurement of cerebral edema. J. Neurosurg. 49, 530-537.

Martinez-Hernandez, A., Bell, K.P., Norenberg, M.D., 1977. Glutamine synthetase: glial localization in brain. Science 195, 13561358.

Master, S., Gottstein, J., Blei, A.T., 1999. Cerebral blood flow and the development of ammonia-induced brain edema in rats after portacaval anastomosis. Hepatology 30, 876-880.

McPhail, M.J.W., Patel, N.R., Taylor-Robinson, S.D., 2012. Brain imaging and hepatic encephalopathy. Clin Liver Dis 16, 57-72.

Mehrotra, A., Trigun, S.K., 2012. Moderate grade hyperammonemia induced concordant activation of antioxidant enzymes is associated with prevention of oxidative stress in the brain slices. Neurochem. Res. 37, 171-181.

Michalak, A., Rose, C., Butterworth, J., Butterworth, R.F., 1996. Neuroactive amino acids and glutamate (NMDA) receptors in frontal cortex of rats with experimental acute liver failure. Hepatology 24, 908-913.

Miller, R.H., Raff, M.C., 1984. Fibrous and protoplasmic astrocytes are biochemically and developmentally distinct. J. Neurosci. 4, 585-592.

Montgomery, J.Y., Bajaj, J.S., 2011. Advances in the evaluation and management of minimal hepatic encephalopathy. Curr Gastroenterol Rep 13, 26-33.

Montoliu, C., Cauli, O., Urios, A., ElMlili, N., Serra, M.A., Giner-Duran, R., González-Lopez, O., Del Olmo, J.A., Wassel, A., Rodrigo, J.M., Felipo, V., 2011. 3-nitro-tyrosine as a peripheral biomarker of minimal hepatic encephalopathy in patients with liver cirrhosis. Am. J. Gastroenterol. 106, 1629-1637.

Montoliu, C., Piedrafita, B., Serra, M.A., Del Olmo, J.A., Urios, A., Rodrigo, J.M., Felipo, V., 2009. IL-6 and IL-18 in blood may discriminate cirrhotic patients with and without minimal hepatic encephalopathy. J. Clin. Gastroenterol. 43, $272-279$.

Mort, D., Marcaggi, P., Grant, J., Attwell, D., 2001. Effect of acute exposure to ammonia on glutamate transport in glial cells isolated from the salamander retina. J. Neurophysiol. 86, 836-844.

Moser, H., 1987. Electrophysiological evidence for ammonium as a substitute for potassium in activating the sodium pump in a crayfish sensory neuron. Can. J. Physiol. Pharmacol. 65, 141-145.

Mpabanzi, L., Jalan, R., 2012. Neurological complications of acute liver failure: Pathophysiological basis of current management and emerging therapies. Neurochemistry International 60, 736-742.

Murthy, C.R., Rama Rao, K.V., Bai, G., Norenberg, M.D., 2001. Ammonia-induced production of free radicals in primary cultures of rat astrocytes. J. Neurosci. Res. 66, 282-288.

Nagelhus, E.A., Horio, Y., Inanobe, A., Fujita, A., Haug, F.M., Nielsen, S., Kurachi, Y., Ottersen, O.P., 1999. Immunogold evidence suggests that coupling of $\mathrm{K}+$ siphoning and water transport in rat retinal Müller cells is mediated by a coenrichment of Kir4.1 and AQP4 in specific membrane domains. Glia 26, 47-54.

Nase, G., Helm, P.J., Enger, R., Ottersen, O.P., 2008. Water entry into astrocytes during brain edema formation. Glia 56, 895-902.

Nico, B., Ribatti, D., 2011. Role of aquaporins in cell migration and edema formation in human brain tumors. Exp. Cell Res. 317, 2391-2396.

Nicolao, F., Efrati, C., Masini, A., Merli, M., Attili, A.F., Riggio, O., 2003. Role of determination of partial pressure of ammonia in cirrhotic patients with and without hepatic encephalopathy. J. Hepatol 38, 441-446.

Nielsen, S., Nagelhus, E.A., Amiry-Moghaddam, M., Bourque, C., Agre, P., Ottersen, O.P., 1997. Specialized membrane domains for water transport in glial cells: high-resolution immunogold cytochemistry of aquaporin-4 in rat brain. J. Neurosci. 17, 171-180.

Norenberg, M.D., 1977. A light and electron microscopic study of experimental portal-systemic (ammonia) encephalopathy. Progression and reversal of the disorder. Lab. Invest. 36, 618-627.

Norenberg, M.D., Baker, L., Norenberg, L.O., Blicharska, J., Bruce-Gregorios, J.H., Neary, J.T., 1991. Ammonia-induced astrocyte swelling in primary culture. Neurochem. Res. 16, 833-836.

Norenberg, M.D., Bender, A.S., 1994. Astrocyte swelling in liver failure: role of glutamine and benzodiazepines. Acta Neurochir Suppl (Wien) 60, 24-27.

Norenberg, M.D., Huo, Z., Neary, J.T., Roig-Cantesano, A., 1997. The glial glutamate transporter in hyperammonemia and hepatic encephalopathy: relation to energy metabolism and glutamatergic neurotransmission. Glia 21, 124-133.

Oberheim, N.A., Takano, T., Han, X., He, W., Lin, J.H.C., Wang, F., Xu, Q., Wyatt, J.D., Pilcher, W., Ojemann, J.G., Ransom, B.R., Goldman, S.A., Nedergaard, M., 2009. Uniquely hominid features of adult human astrocytes. J. Neurosci. 29, 3276-3287.

Olson, J.E., Li, G.Z., 2000. Osmotic sensitivity of taurine release from hippocampal neuronal and glial cells. Adv. Exp. Med. Biol. 483, 213-218.

Bosoi, C.R. \& Rose, C.F., 2013. Brain edema in acute liver failure and chronic liver disease: Similarities and differences. Neurochemistry International, 62(4), p.446-457. 
Ong, J.P., Aggarwal, A., Krieger, D., Easley, K.A., Karafa, M.T., Lente, F.V., Arroliga, A.C., Mullen, K.D., 2003. Correlation between ammonia levels and the severity of hepatic encephalopathy. Am J Med 114, 188-193.

Oria, M., Chatauret, N., Chavarria, L., Romero-Giménez, J., Palenzuela, L., Pardo-Yules, B., Arranz, J.A., Bodega, G., Raguer, N., Córdoba, J., 2010. Motor-evoked potentials in awake rats are a valid method of assessing hepatic encephalopathy and of studying its pathogenesis. Hepatology 52, 2077-2085.

Oria, M., Romero-Giménez, J., Arranz, J.A., Riudor, E., Raguer, N., Córdoba, J., 2012. Ornithine phenylacetate prevents disturbances of motor-evoked potentials induced by intestinal blood in rats with portacaval anastomosis. Journal of Hepatology 56, 109114.

Ostapowicz, G., Fontana, R.J., Schiødt, F.V., Larson, A., Davern, T.J., Han, S.H.B., McCashland, T.M., Shakil, A.O., Hay, J.E., Hynan, L., Crippin, J.S., Blei, A.T., Samuel, G., Reisch, J., Lee, W.M., 2002. Results of a prospective study of acute liver failure at 17 tertiary care centers in the United States. Ann. Intern. Med. 137, 947-954.

Pasantes-Morales, H., Cruz-Rangel, S., 2010. Brain volume regulation: osmolytes and aquaporin perspectives. Neuroscience 168, 871-884.

Pellerin, L., Magistretti, P.J., 2011. Sweet sixteen for ANLS. Journal of Cerebral Blood Flow \& Metabolism.

Pierre, K., Pellerin, L., 2005. Monocarboxylate transporters in the central nervous system: distribution, regulation and function. J. Neurochem. 94, 1-14.

Potvin, M., Finlayson, M.H., Hinchey, E.J., Lough, J.O., Goresky, C.A., 1984. Cerebral abnormalities in hepatectomized rats with acute hepatic coma. Lab. Invest. 50, 560-564.

Poveda, M.-J., Bernabeu, A., Concepción, L., Roa, E., De Madaria, E., Zapater, P., Pérez-Mateo, M., Jover, R., 2010. Brain edema dynamics in patients with overt hepatic encephalopathy A magnetic resonance imaging study. Neuroimage 52, 481-487.

Preuss, M., 2012. An energy-failure based brain edema concept. Med. Hypotheses 79, 259-260.

Rai, V., Nath, K., Saraswat, V.A., Purwar, A., Rathore, R.K.S., Gupta, R.K., 2008. Measurement of cytotoxic and interstitial components of cerebral edema in acute hepatic failure by diffusion tensor imaging. J Magn Reson Imaging 28, 334-341.

Rama Rao, K.V., Chen, M., Simard, J.M., Norenberg, M.D., 2003. Increased aquaporin-4 expression in ammonia-treated cultured astrocytes. Neuroreport 14, 2379-2382.

Rama Rao, K.V., Reddy, P.V.B., Tong, X., Norenberg, M.D., 2010. Brain edema in acute liver failure: inhibition by L-histidine. Am. J. Pathol. 176, 1400-1408.

Ranjan, P., Mishra, A.M., Kale, R., Saraswat, V.A., Gupta, R.K., 2005. Cytotoxic edema is responsible for raised intracranial pressure in fulminant hepatic failure: in vivo demonstration using diffusion-weighted MRI in human subjects. Metab Brain Dis 20, 181192.

Rao, K.V.R., Panickar, K.S., Jayakumar, A.R., Norenberg, M.D., 2005. Astrocytes protect neurons from ammonia toxicity. Neurochem. Res 30, 1311-1318.

Rao, K.V.R., Reddy, P.V.B., Curtis, K.M., Norenberg, M.D., 2011. Aquaporin-4 expression in cultured astrocytes after fluid percussion injury. J. Neurotrauma 28, 371-381.

Rash, J.E., Yasumura, T., Hudson, C.S., Agre, P., Nielsen, S., 1998. Direct immunogold labeling of aquaporin-4 in square arrays of astrocyte and ependymocyte plasma membranes in rat brain and spinal cord. Proc. Natl. Acad. Sci. U.S.A. 95, 11981-11986.

Rengachary, S.S. and Ellenbogen, R.G., 2005. Principles of Neurosurgery. Elsevier Mosby, Edinburgh.

Rose, C., Ytrebø, L.M., Davies, N.A., Sen, S., Nedredal, G.I., Belanger, M., Revhaug, A., Jalan, R., 2007. Association of reduced extracellular brain ammonia, lactate, and intracranial pressure in pigs with acute liver failure. Hepatology 46, 1883-1892.

Rose, C.F., 2010. Increase brain lactate in hepatic encephalopathy: cause or consequence? Neurochem. Int. 57, 389-394.

Rose, C.F., 2012. Ammonia-lowering strategies for the treatment of hepatic encephalopathy. Clin. Pharmacol. Ther. 92, $321-331$.

Rosen, H.R., 2011. Clinical practice. Chronic hepatitis C infection. N. Engl. J. Med. 364, 2429-2438.

Rothstein, J.D., Martin, L., Levey, A.I., Dykes-Hoberg, M., Jin, L., Wu, D., Nash, N., Kuncl, R.W., 1994. Localization of neuronal and glial glutamate transporters. Neuron 13, 713-725.

Rovira, A., Córdoba, J., Sanpedro, F., Grivé, E., Rovira-Gols, A., Alonso, J., 2002. Normalization of T2 signal abnormalities in hemispheric white matter with liver transplant. Neurology 59, 335-341.

Rovira, A., Mínguez, B., Aymerich, F.X., Jacas, C., Huerga, E., Córdoba, J., Alonso, J., 2007. Decreased white matter lesion volume and improved cognitive function after liver transplantation. Hepatology 46, 1485-1490.

Saksena, S., Rai, V., Saraswat, V.A., Rathore, R.S., Purwar, A., Kumar, M., Thomas, M.A., Gupta, R.K., 2008. Cerebral diffusion tensor imaging and in vivo proton magnetic resonance spectroscopy in patients with fulminant hepatic failure. J. Gastroenterol. Hepatol. 23, e111-119.

Sanyal, A.J., Mullen, K.D., Bass, N.M., 2010. The treatment of hepatic encephalopathy in the cirrhotic patient. Gastroenterology \& hepatology 6,1-12.

Sawara, K., Desjardins, P., Chatauret, N., Kato, A., Suzuki, K., Butterworth, R.F., 2009. Alterations in expression of genes coding for proteins of the neurovascular unit in ischemic liver failure. Neurochem. Int. 55, 119-123.

Schneider, G.H., Baethmann, A., Kempski, O., 1992. Mechanisms of glial swelling induced by glutamate. Can. J. Physiol. Pharmacol. 70 Suppl, S334-343.

Sen, S., Rose, C., Ytrebø, L.M., Davies, N.A., Nedredal, G.I., Drevland, S.S., Kjønnø, M., Prinzen, F.W., Hodges, S.J., Deutz, N.E.P., Williams, R., Butterworth, R.F., Revhaug, A., Jalan, R., 2006. Effect of albumin dialysis on intracranial pressure increase in pigs with acute liver failure: a randomized study. Crit. Care Med. 34, 158-164.

Shah, N.J., Neeb, H., Kircheis, G., Engels, P., Häussinger, D., Zilles, K., 2008. Quantitative cerebral water content mapping in hepatic encephalopathy. Neuroimage 41, 706-717.

Bosoi, C.R. \& Rose, C.F., 2013. Brain edema in acute liver failure and chronic liver disease: Similarities and differences. Neurochemistry International, 62(4), p.446-457. 
Shawcross, D.L., Davies, N.A., Williams, R., Jalan, R., 2004. Systemic inflammatory response exacerbates the neuropsychological effects of induced hyperammonemia in cirrhosis. J. Hepatol. 40, 247-254.

Shimojima, N., Eckman, C.B., McKinney, M., Sevlever, D., Yamamoto, S., Lin, W., Dickson, D.W., Nguyen, J.H., 2008. Altered expression of zonula occludens-2 precedes increased blood-brain barrier permeability in a murine model of fulminant hepatic failure. J Invest Surg 21, 101-108.

Skowrońska, M., Zielińska, M., Wójcik-Stanaszek, L., Ruszkiewicz, J., Milatovic, D., Aschner, M., Albrecht, J., 2012. Ammonia increases paracellular permeability of rat brain endothelial cells by a mechanism encompassing oxidative/nitrosative stress and activation of matrix metalloproteinases. J. Neurochem. 121, 125-134.

Song, Y.J.C., Halliday, G.M., Holton, J.L., Lashley, T., O’Sullivan, S.S., McCann, H., Lees, A.J., Ozawa, T., Williams, D.R., Lockhart, P.J., Revesz, T.R., 2009. Degeneration in different parkinsonian syndromes relates to astrocyte type and astrocyte protein expression. J. Neuropathol. Exp. Neurol. 68, 1073-1083.

Staub, F., Baethmann, A., Peters, J., Weigt, H., Kempski, O., 1990. Effects of lactacidosis on glial cell volume and viability. J. Cereb. Blood Flow Metab. 10, 866-876.

Strauss, G., Hansen, B.A., Kirkegaard, P., Rasmussen, A., Hjortrup, A., Larsen, F.S., 1997. Liver function, cerebral blood flow autoregulation, and hepatic encephalopathy in fulminant hepatic failure. Hepatology 25, 837-839.

Suárez, I., Bodega, G., Fernández, B., 2000. Modulation of glutamate transporters (GLAST, GLT-1 and EAAC1) in the rat cerebellum following portocaval anastomosis. Brain Res. 859, 293-302.

Sugimoto, R., Iwasa, M., Maeda, M., Urawa, N., Tanaka, H., Fujita, N., Kobayashi, Y., Takeda, K., Kaito, M., Takei, Y., 2008. Value of the Apparent Diffusion Coefficient for Quantification of Low-Grade Hepatic Encephalopathy. Am J Gastroenterol 103, $1413-1420$.

Tofteng, F., Hauerberg, J., Hansen, B.A., Pedersen, C.B., Jørgensen, L., Larsen, F.S., 2006. Persistent arterial hyperammonemia increases the concentration of glutamine and alanine in the brain and correlates with intracranial pressure in patients with fulminant hepatic failure. J. Cereb. Blood Flow Metab. 26, 21-27.

Tofteng, F., Jorgensen, L., Hansen, B.A., Ott, P., Kondrup, J., Larsen, F.S., 2002. Cerebral microdialysis in patients with fulminant hepatic failure. Hepatology 36, 1333-1340.

Traber, P.G., Dal Canto, M., Ganger, D.R., Blei, A.T., 1987. Electron microscopic evaluation of brain edema in rabbits with galactosamine-induced fulminant hepatic failure: ultrastructure and integrity of the blood-brain barrier. Hepatology 7, 12721277.

Trzepacz, P.T., Tarter, R.E., Shah, A., Tringali, R., Faett, D.G., Van Thiel, D.H., 1994. SPECT scan and cognitive findings in subclinical hepatic encephalopathy. J Neuropsychiatry Clin Neurosci 6, 170-175.

Vaquero, J., Chung, C., Blei, A.T., 2004. Cerebral blood flow in acute liver failure: a finding in search of a mechanism. Metab Brain Dis 19, 177-194.

Varoqui, H., Zhu, H., Yao, D., Ming, H., Erickson, J.D., 2000. Cloning and functional identification of a neuronal glutamine transporter. J. Biol. Chem. 275, 4049-4054.

Wang, Y., Beydoun, M.A., 2007. The obesity epidemic in the United States--gender, age, socioeconomic, racial/ethnic, and geographic characteristics: a systematic review and meta-regression analysis. Epidemiol Rev 29, 6-28.

Weissenborn, K., Ahl, B., Fischer-Wasels, D., Van den Hoff, J., Hecker, H., Burchert, W., Köstler, H., 2007. Correlations between magnetic resonance spectroscopy alterations and cerebral ammonia and glucose metabolism in cirrhotic patients with and without hepatic encephalopathy. Gut 56, 1736-1742.

Wendon, J.A., Harrison, P.M., Keays, R., Williams, R., 1994. Cerebral blood flow and metabolism in fulminant liver failure. Hepatology 19, 1407-1413.

Willard-Mack, C.L., Koehler, R.C., Hirata, T., Cork, L.C., Takahashi, H., Traystman, R.J., Brusilow, S.W., 1996. Inhibition of glutamine synthetase reduces ammonia-induced astrocyte swelling in rat. Neuroscience 71, 589-599.

Wright, G., Davies, N.A., Shawcross, D.L., Hodges, S.J., Zwingmann, C., Brooks, H.F., Mani, A.R., Harry, D., Stadlbauer, V., Zou, Z., Zou, Z., Williams, R., Davies, C., Moore, K.P., Jalan, R., 2007. Endotoxemia produces coma and brain swelling in bile duct ligated rats Hepatology 45, 1517-1526.

Wright, G., Soper, R., Brooks, H.F., Stadlbauer, V., Vairappan, B., Davies, N.A., Andreola, F., Hodges, S., Moss, R.F., Davies, D.C., Jalan, R., 2010. Role of aquaporin-4 in the development of brain oedema in liver failure. J. Hepatol. 53, 91-97.

Yamamoto, S., Nguyen, J.H., 2006. TIMP-1/MMP-9 imbalance in brain edema in rats with fulminant hepatic failure. J. Surg. Res. $134,307-314$.

Ytrebø, L.M., Kristiansen, R.G., Maehre, H., Fuskevåg, O.M., Kalstad, T., Revhaug, A., Cobos, M.J., Jalan, R., Rose, C.F., 2009. Lornithine phenylacetate attenuates increased arterial and extracellular brain ammonia and prevents intracranial hypertension in pigs with acute liver failure. Hepatology 50, 165-174.

Ziemińska, E., Dolińska, M., Lazarewicz, J.W., Albrecht, J., 2000. Induction of permeability transition and swelling of rat brain mitochondria by glutamine. Neurotoxicology 21, 295-300.

Zou, J., Wang, Y.-X., Dou, F.-F., Lü, H.-Z., Ma, Z.-W., Lu, P.-H., Xu, X.-M., 2010. Glutamine synthetase down-regulation reduces astrocyte protection against glutamate excitotoxicity to neurons. Neurochem. Int. 56, 577-584.

Zwingmann, C., Chatauret, N., Leibfritz, D., Butterworth, R.F., 2003. Selective increase of brain lactate synthesis in experimental acute liver failure: results of a [H-C] nuclear magnetic resonance study. Hepatology 37, 420-428.

Zwingmann, C., Chatauret, N., Rose, C., Leibfritz, D., Butterworth, R.F., 2004. Selective alterations of brain osmolytes in acute liver failure: protective effect of mild hypothermia. Brain Res. 999, 118-123.

Bosoi, C.R. \& Rose, C.F., 2013. Brain edema in acute liver failure and chronic liver disease: Similarities and differences. Neurochemistry International, 62(4), p.446-457. 